\title{
GLOBAL BUSINESS AND FINANCIAL CYCLES: A TALE OF TWO CAPITAL ACCOUNT REGIMES
}

\author{
Julien Acalin \\ Alessandro Rebucci \\ Working Paper 27739 \\ http://www.nber.org/papers/w27739 \\ NATIONAL BUREAU OF ECONOMIC RESEARCH \\ 1050 Massachusetts Avenue \\ Cambridge, MA 02138 \\ August 2020
}

Paper prepared for the 2019 Seoul Journal of Economics International Symposium. We thank the editor, Soyoung Kim, and conference participants for helpful comments and suggestions. We are also grateful to M. Hashem Pesaran, Ambrogio Cesa-Bianchi, and Andrew Rose for discussions and comments. The remaining errors are ours. The views expressed herein are those of the authors and do not necessarily reflect the views of the National Bureau of Economic Research.

NBER working papers are circulated for discussion and comment purposes. They have not been peer-reviewed or been subject to the review by the NBER Board of Directors that accompanies official NBER publications.

(C) 2020 by Julien Acalin and Alessandro Rebucci. All rights reserved. Short sections of text, not to exceed two paragraphs, may be quoted without explicit permission provided that full credit, including $(\odot)$ notice, is given to the source. 
Global Business and Financial Cycles: A Tale of Two Capital Account Regimes

Julien Acalin and Alessandro Rebucci

NBER Working Paper No. 27739

August 2020

JEL No. C38,E42,F44,G15

\begin{abstract}
$\underline{\text { ABSTRACT }}$
Using a new equity price-based measure of the global financial cycle, this paper evaluates the relative importance of global financial shocks for quarterly equity returns and output growths in a large sample of advanced and emerging economies, as well as in South Korea and China--two countries on different sides of the trilemma triangle of international finance. We document that global financial shocks in both China and South Korea explain a substantial share of equity return variability (20 and 50 percent of the total variance, respectively), but a much smaller portion of real output fluctuations (less than 10 percent in Korea and negligible in the case of China). We also find that the combination of a closer capital account and a more rigid exchange rate regime, as in China, is associated with some costs in terms of diversification opportunities quantified by very large exposures to domestic financial and real shocks, dwarfing the contribution of any other shock in the model. More surprisingly, the combination of a relatively open capital account and a flexible exchange rate, as in South Korea, not only is associated with higher exposure to the global financial cycle than in China but also with a significant incidence of domestic financial shocks on output fluctuations.
\end{abstract}

\author{
Julien Acalin \\ Johns Hopkins University \\ 3100 Wyman Park Drive \\ Baltimore, MD 21211 \\ jacalin1@jhu.edu \\ Alessandro Rebucci \\ Johns Hopkins Carey Business School \\ 100 International Drive \\ Baltimore, MD 21202 \\ and NBER \\ arebucci@jhu.edu
}


Rey (2013): There is a global financial cycle in capital flows (GFC), asset prices, and in credit growth. The cycle co-moves with the VIX Index, a measure of uncertainty and risk aversion of the markets. [...] Analysis suggests that one of the determinants of the GFC is monetary policy in the center country. [...] Whenever capital is freely mobile, the global financial cycle constrains national monetary policies regardless of the exchange rate regime.

Cerutti et al. (2017): Our evidence seems mostly inconsistent with a significant and conspicuous GFC for capital flows. [...] Succinctly, most variation in capital flows does not seem to be the result of common shocks nor stem from observables in a central country like the United States.

\section{Introduction}

In a celebrated speech in Jackson Hole, Rey (2013) argued that there is a global financial cycle (GFC) in capital flows and asset prices, mainly driven by fluctuations in risk aversion and monetary conditions in the center economies. Rey (2013) further observed that the GFC transforms the Mundell-Fleming trilemma of international finance into a dilemma, calling for macro-prudential policies and capital controls to manage the impact of the GFC on small open economies. Cerutti, Claessens, and Rose (2017), in sharp contrast, maintained that there is no evidence of a conspicuous GFC driving capital flows in most countries and most of the time.

Neither proponents nor opponents of the GFC hypothesis, however, as well as most the ensued literature, has evaluated the importance of the GFC for final macroeconomic outcomes-such as output, investment, and consumption-that ultimately matter to evaluate economic performance. Moreover, while capital controls and macro-prudential policies are well understood theoretically, empirical evaluation of their insulating properties suffers from limitations arising from the difficulty to identify their causal macroeconomic effects and the limited external validity of studies based on microeconomic data at the household and firm level. ${ }^{1}$

This paper's contribution is twofold. First, we evaluate the GFC hypothesis for both equity prices and real macroeconomic outcomes in a theoretically coherent framework for a large sample of advanced and emerging economies. Second, by comparing two specific countries on different sides of the trilemma triangle, South Korea and China, we can assess the insulating properties of a closed

\footnotetext{
${ }^{1}$ For recent surveys of the literature on capital controls and macroprudential policies, see Engel (2016), Erten, Korinek, and Ocampo (forthcoming), Rebucci and Ma (2020).
} 
capital account regime compared to an open one operating under exchange rate flexibility.

We document that global financial shocks in both China and South Korea explain a substantial share of equity return variability (20 and 50 percent of total variance, respectively), but a much smaller portion of real output fluctuations (less than 10 percent in Korea and negligible in the case of China). We also find that a closer capital account with a more rigid exchange rate regime, as in China, is associated with some costs in terms of lost diversification opportunities quantified by very large exposures to domestic financial and real shocks dwarfing the contribution of any other shock in the model. More surprisingly, a more open capital account with a flexible exchange rate, as in South Korea, not only is associated with a higher exposure to the global financial cycle but also with an important incidence of domestic financial shocks on output fluctuations.

While the GFC hypothesis applies to a wide range of assets and to capital flows, this paper focuses on international co-movement in country equity returns and output growth rates at the quarterly frequency. To model the interaction between the business and financial cycles, we take a common factor approach in the context of the factor-augmented Panel VAR (PVAR) econometric model proposed by Cesa-Bianchi, Pesaran, and Rebucci (2019)-henceforth, CPR. Hence, we assume that business and financial cycles are driven by two common shocks and two idiosyncratic shocks for each country in the sample in a complete multi-country model of the world economy.

Identification of the two common shocks exploits different patterns of cross-country correlations of quarterly equity market returns and GDP growth rates, consistent with the stylized facts of the data that we document in the paper and standard arbitrage asset pricing theory as for instance in Ross (1976), Chamberlain and Rothschild (1982) and Sentana (2002), where it is assumed that the idiosyncratic risk component of asset returns is weakly correlated across section and not priced in the returns. ${ }^{2}$

From a theoretical perspective, one can assume that country-specific output growth is the dividend or endowment growth process of a Lucas (1978) tree economy. In a heterogeneous multi-country version of the Lucas (1978) model, CPR show that country-specific equity returns are driven by at least one more risk factor than the world growth risk factor shared by country endowments. Furthermore, assuming that no country is a dominant unit, in the sense that it cannot influence world aggregates, and that the endowment growth innovations are weakly correlated across countries, CPR

\footnotetext{
${ }^{2}$ In the paper, a panel time series is defined as weakly correlated if the maximum eigenvalue of its covariance matrix is bounded as the size of the cross section increases.
} 
show that the average output growth in the sample is the only common factor in the cross section of country-specific output growths. As a consequence, by combining all common shocks to equity returns other than the world growth factor in a second composite common shock, it is possible to capture the cross-country correlation of the equity return series unexplained by the first factor in a single second common financial risk factor.

Consistent with this theoretical framework, we specify a multi-country econometric model in output growths and equity returns with two common shocks and two country-specific shocks. To identify the two common shocks, we assume that the first one, which we refer to as the world or international business cycle shock, is common to both GDP growths and equity returns in all countries, while the second that we refer to as the global financial cycle shock, is only shared among the return series after controlling for international business cycle innovations. To identify the two country-specific shocks, instead, we exploit the empirical properties of the estimated multi-country covariance matrix combined with alternative auxiliary assumptions typically used in the literature. Note, however, that the identification of the two common shocks does not require any restrictions on the within-country correlation of country-specific returns and output growth shocks.

These moment restrictions not only are consistent with the consumption-based asset pricing theory embedded in our econometric model, but they also fit well the stylized facts of the data. Specifically, we will show that equity returns and output growths are closely correlated (unconditionally) across countries, but this cross-country correlation is much stronger for returns than for growth. Second, conditional on the estimated common factor shocks, the estimated country-specific innovations display cross-country correlations that are consistent with the identification assumptions made and their interpretation as sources of idiosyncratic risk that can be diversified internationally. Finally, we will also illustrate that the estimated multi-country covariance matrix of the country-specific shocks is near diagonal, suggesting that the two common shocks capture most of the contemporaneous correlation among them.

The empirical analysis yields a rich set of results. First, we provide a new estimate of the global financial cycle that tracks very well the updated GFC measure of Miranda-Agrippino and Rey (2020) (henceforth, MAR), even though it is based on a single asset class. Our parsimonious estimate of the GFC correlates closely with the U.S. Federal Fund rate and the ECB Eonia rate. It also characterizes global financial booms and busts more markedly than the MAR measure, including particularly 
during the 2010-12 European crisis and subsequent recovery supported by unconventional monetary policies in advanced economies.

Second, consistent with the GFC hypothesis, we find that global financial shocks are a major driver of individual country equity markets, explaining more than 50 percent of the variance in the average economy in the sample as well as in South Korea. In contrast, in the case of China, global financial shocks have a much lower impact. Yet, they still account for more than 20 percent of the variance in domestic equity returns.

Third, not necessarily consistent with the the implications of the GFC hypothesis and more in line with the evidence of Cerutti et al. (2017), we show that global financial shocks have a much more limited impact on countries' business cycles. Global financial shocks explain about 10 percent of the forecast error variance of output growth in the average economy as well as in Korea, and have virtually no impact on China's output fluctuations.

Fourth, and quite surprisingly, we find that country-specific financial shocks, which can be interpreted as representing idiosyncratic risk in our econometric model, explain no share of output variance in China or the average economy in the sample, while they have a contribution to output variance comparable to that of the global financial shocks in the case of Korea, which is an outlier in our sample in this particular respect.

Finally, we report some evidence of a possible trade-off between exposure to global factors and lower diversification opportunities of idiosyncratic risks, in Korea and China, respectively. In particular, the better insulation of China's stock market to the GFC factor is associated with a very large exposure of the local stock market to domestic financial shocks. Similarly, home-grown real shocks play a much larger role in explaining Chinese output fluctuations. By the same token, Korea's better financial diversification opportunities associated with an open capital account result in a lower sensitivity of the domestic stock market to idiosyncratic financial shocks. Yet, we find that this lower sensitivity of the local stock market to home grown financial disturbances does not translates into a smaller exposure of the Korean business cycle to country-specific financial shocks. As noted already, this latter finding is peculiar to South Korea and does not apply to the average economy in the sample. An interesting area of future research, therefore, in the specific case of Korea, is to try to separate the role of capital account openness from that of exchange rate flexibility.

The literature on the GFC is voluminous. Here we define our contributions relative to the most 
closely related papers. A few other studies evaluate the interaction of international business and financial cycles. Ha, Kose, Otrok, and Prasad (2020) look at a wider set of financial and real variables, including interest rates, house prices, consumption and investment, in addition to equity prices and output, but restrict the empirical analysis to the G7 countries. While we focus on GDP growth rates and stock market returns, we provide evidence based on a much larger country sample of emerging and advanced economies. In addition, we identify the international business and global financial cycle shocks based on a set of explicit theory and data-consistent assumptions. Cesa-Bianchi, Ferrero, and Rebucci (2018) identify an international credit supply shock in the time series dimension from changes in broker-dealer leverage in the United States. They show that residential house prices, cross-border BIS claims, consumption and output growths comove strongly conditional on this shock that explains about 10-20 percent of a capital flows variance and 10-15 percent of consumption variance, on average, in a sample of about 50 advanced and emerging economies (excluding the United States). ${ }^{3}$ Despite using different econometric methods, country samples, and variables, these studies find remarkably similar results showing limited spillovers from the global financial cycle to countries' business cycles. ${ }^{4}$

Other papers investigate the insulating power of capital controls and the heterogeneous sensitivity of different economies to the GFC. Zeev (2017) investigates whether capital controls can help countries to mitigate the impact of an international credit shock. He documents that countries at the 75th percentile of the distribution of an index of capital inflow controls are much more shielded relative to countries at the 25 th percentile. Cesa-Bianchi et al. (2018), however, shows that, while higher loan-to-value ratios and lower share of foreign currency denominated liabilities, as well as more flexible exchange rate regimes, are associated with lower consumption sensitivity to the international credit supply shock that they identify, controls on capital inflows are not, except for a few exceptional cases like China. Han and Wei (2018) re-examine the international transmissions of monetary policy shocks from advanced economies to emerging economies. They document a pattern between the trilemma and the dilemma: without capital controls, a flexible exchange rate offers some monetary autonomy when the center country tightens its monetary policy, yet it fails to do so when the center country loosens the policy stance. In contrast, capital controls help to insulate the periphery from

\footnotetext{
${ }^{3}$ Cesa-Bianchi, Cespedes, and Rebucci (2015) identify a global liquidity shock as the common component of BIS cross-border claims finding similar results.

${ }^{4} \mathrm{CPR}$ also document similar results using equity market realized volatility rather than stock returns. CPR, however, do not focus explicitly on the GFC or the country-specific determinants of the exposure to it.
} 
center country monetary policy shocks even when the latter lowers its interest rate. We provide both cross-section and country-study evidence on these issues in a unified empirical framework.

Related to this, Ma, Rogers, and Zhou (2019) study a Chinese stock market liberalization episode in the mid-2010s-the so called Shanghai-Hong Kong Stock Connect. The connect program allowed investors based in China, Hong Kong residents, and foreign investors to trade freely some stocks listed on both markets. Using a difference-in-difference approach, Ma et al. (2019) show that, after the introduction of the connect program, firm-level investment in China became more sensitive to U.S. monetary policy shocks, suggesting that capital controls were effective at insulating real domestic variables before their removal. Gourinchas (2018) extends the Mundell-Fleming model of a small open economy with financial spillovers from center economies, and shows that the stabilizing properties of flexible exchange rates diminish with the strength of the financial spillovers. In particular, for sufficiently strong financial spillovers the economy faces a dilemma and flexible exchange rates become ineffective as in Rey (2013). Yet, if financial spillovers are present but not strong enough to alter the transmission of domestic monetary policy-as for instance is the case for Chile-then the economy still faces a trilemma and flexible exchange rates help stabilize the economy. We compare directly the performance of two countries with polar capital account and exchange rate regimes, finding that China is more insulated than South Korea from GFC shocks, providing an example of a possible loss of effectiveness of the exchange rate regime as an insulation mechanism in the case of Korea and confirming the exceptional nature of the Chinese case.

Regarding our identification strategy, other studies have observed that the cross-country correlation in asset prices is much stronger for equity returns than for output growth. Tesar (1995), Colacito and Croce (2011), Lewis and Liu (2015) highlight similar patterns of cross-country correlations for equity returns and consumption growth. Bai et al. (2019) document that emerging market sovereign spreads are much more correlated across countries than their economic conditions. None of these studies, however, exploit these moment of the data for factor identification purposes. We use these stylized facts to identify two common shocks in a factor-augmented multi-country Panel VAR model (PVAR) as in CPR.

The rest of the paper is organized as follows. Section 2 presents the empirical multi-country model that we use and discusses the identification of the common and country-specific shocks. Section 3 reports key stylized facts of the data that guide the shock identification. Section 4 reports the 
empirical results. Section 5 concludes. Some additional results are reported in the appendix.

\section{$2 \quad$ Empirical model}

The framework that we apply is a multi-country factor model developed by Cesa-Bianchi, Pesaran, and Rebucci (2019) to which we refer for technical details. This is a factor-augmented, panel vector autoregression (PVAR) in which quarterly country-specific output growths and stock market equity returns are driven by 2 common and $2 \times N$ country-specific shocks. In this section, we discuss the identification of the common shocks and the specification of the estimation equations used to assess their relative importance for South Korea and China in the context of a complete multi-country model of the world economy. Identification of the country-specific shocks plays only an auxiliary role in the empirical analysis and follows a conventional approach that is also briefly summarized below.

Consider, without loss of generality, the following first-order PVAR in stock market equity returns, $r_{i t}$, and output growths, $\Delta y_{i t}$, for $i=1,2, \ldots, N$ and $t=1,2, \ldots, T$

$$
\begin{aligned}
r_{i t} & =a_{i r}+\phi_{i, 11} r_{i, t-1}+\phi_{i, 12} \Delta y_{i, t-1}+e_{i r, t}, \\
\Delta y_{i t} & =a_{i y}+\phi_{i, 21} r_{i, t-1}+\phi_{i, 22} \Delta y_{i, t-1}+e_{i y, t}
\end{aligned}
$$

where equity returns, $r_{i t}$, are measured as the log-difference of the stock market index for country $i$ during quarter $t$, output growths, $\Delta y_{i t}$, are measured as the log-difference of real GDP, and $e_{i r, t}$ and $e_{i y, t}$ are country-specific reduced-form innovations assumed to be serially uncorrelated. Consistent with classical asset pricing theory (e.g., Lucas (1978) and Ross (1976)), CPR posit the following unobservable factor representation for the reduced-form PVAR innovations:

$$
\begin{aligned}
e_{i r, t} & =\lambda_{i} \zeta_{t}+\theta_{i} \xi_{t}+\eta_{i t} \\
e_{i y, t} & =\gamma_{i} \zeta_{t}+\varepsilon_{i t}
\end{aligned}
$$

where $\zeta_{t}$ and $\xi_{t}$ are two common shocks to market factors, while $\eta_{i t}$ and $\varepsilon_{i t}$ are two country-specific shocks representing idiosyncratic risk that is not priced in the returns. Thus, they are assumed to be serially uncorrelated, weakly correlated across countries as in Chamberlain and Rothschild (1982) and Sentana (2002), but possibly correlated with each other within each country. As we will see in 
our application, the innovation factor-structure implied by Equations (1)-(4) has strong empirical support in the data.

The econometric model in Equations (1)-(4) states that the country-specific equity returns include at least one more common shock, $\xi_{t}$, than the output growths, capturing all common higher-moment components not accounted for by the first common shock, $\zeta_{t}$, driving the cash flow or endowment processes. As we shall see below, the common shock $\zeta_{t}$ in (4) can be extracted from the panel of quarterly GDP growth series alone. Therefore, it will be labelled "international or global business cycle shock". The second common shock, $\xi_{t}$, instead, can be shown to be a linear combination of all other common shocks in the heterogeneous multi-country asset pricing model of CPR, reflecting second and higher-order moment common innovations, their squares and cross products. Empirically, this shock also captures changes in non-fundamental aspects of financial markets, such as overreactions to news due to excessive optimism/pessimism or bubble components that are ruled out by the solution of the theoretical model. For this reason, we refer to $\xi_{t}$ as the "global financial cycle shock" or "global financial shock" for short. Similarly, $\varepsilon_{i t}$ has a more direct mapping into a countryspecific, and hence idiosyncratic "endowment growth shock" shock, while $\eta_{i t}$ is an all-encompassing country-specific financial shock. We now discuss the intuition for the identification of the common and the idiosyncratic shocks, in turn, and spell out the estimation equations to evaluate their relative importance for country cycles, in particular for South Korea and China.

\subsection{Identification of the Common Shocks in a Static Heterogeneous Setting}

Identification of $\zeta_{t}$ and $\xi_{t}$ and their loadings, $\lambda_{i}, \gamma_{i}$, and $\theta_{i}$ relies on placing restrictions on the cross-country correlations of $\varepsilon_{i t}$ and $\eta_{i t}$, while leaving their within-country correlation unrestricted. To illustrate the mechanics and the intuition on how the identification strategy works, denote world GDP growth and the world equity return by $\Delta \bar{y}_{\omega, t}$ and $\bar{r}_{\omega, t}$, respectively, and suppose that they can be measured by the weighted cross section averages of country-specific output growth and equity returns, namely:

$$
\Delta \bar{y}_{\omega, t}=\sum_{i=1}^{N} w_{i} \Delta y_{i t}, \quad \text { and } \quad \bar{r}_{\omega, t}=\sum_{i=1}^{N} \stackrel{\circ}{w}_{i} r_{i t}
$$

where $\mathbf{w}=\left(w_{1}, w_{2}, \ldots, w_{N}\right)^{\prime}$ and $\stackrel{\circ}{\mathbf{w}}=\left(\stackrel{\circ}{w}_{1}, \stackrel{\circ}{w}_{2}, \ldots, \stackrel{\circ}{w}_{N}\right)^{\prime}$ are $N \times 1$ vectors of aggregation weights, which can be the same or differ.

Let us now make the following assumptions: (i) the loadings $\lambda_{i}, \gamma_{i}$, and $\theta_{i}$ are such that $\zeta_{t}$ is 
a strong (or pervasive) factor for both the panels of equity returns and output growths, while $\xi_{t}$ is a strong factor for the panel of equity returns only; (ii) the weights, $\mathbf{w}$ and $\stackrel{\mathbf{w}}{\mathrm{s}}$, are granular in the sense that individual countries' contribution to world growth and world equity returns are of order $1 / N$; and (iii) that the country-specific shocks, $\varepsilon_{i t}$ and $\eta_{i t}$, are weakly correlated across countries in the sense that

$$
\varrho_{\max }\left(\boldsymbol{\Sigma}_{\varepsilon \varepsilon}\right)=O(1), \quad \text { and } \quad \varrho_{\max }\left(\boldsymbol{\Sigma}_{\eta \eta}\right)=O(1)
$$

where $\boldsymbol{\Sigma}_{\varepsilon \varepsilon}=\operatorname{Var}\left(\varepsilon_{t}\right)$ and $\boldsymbol{\Sigma}_{\eta \eta}=\operatorname{Var}\left(\boldsymbol{\eta}_{t}\right)$ denote the covariance matrices of the $N \times 1$ vectors $\boldsymbol{\varepsilon}_{t}=\left(\varepsilon_{1 t}, \varepsilon_{2 t}, \ldots, \varepsilon_{N t}\right)^{\prime}$ and $\boldsymbol{\eta}_{t}=\left(\eta_{1 t}, \eta_{2 t}, \ldots, \eta_{N t}\right)^{\prime}$, respectively, and $\varrho_{\max }(\boldsymbol{\Sigma})$ is the largest eigenvalue of $\boldsymbol{\Sigma}$, assumed to be bounded in Equation 6 .

Assumption (i) is standard in the factor literature (see, for instance, Assumption B in Bai and $\mathrm{Ng}$ (2002)) and allows for consistent estimation of the common shocks by cross section averaging of country-specific observations (Chudik, Pesaran, and Tosetti (2011)). Assumption (ii) requires that no individual unit is important enough to influence the world aggregates, consistent with the notion that, since the mid-1990s, when our sample period starts, world growth and world equity markets have become progressively more diversified and integrated as a result of the globalization process. ${ }^{5}$ Assumption (iii) is the most important source of identification and requires that the country-specific shocks, $\varepsilon_{i t}$ and $\eta_{i t}$, can be treated as idiosyncratic risk for asset pricing purposes in line with the approximate factor models of Chamberlain and Rothschild (1982) and Sentana (2002).

Dropping intercepts and dynamics from (1)-(4), the following model for world equity return and GDP growth obtains:

$$
\begin{aligned}
\bar{r}_{\omega, t} & =\lambda \zeta_{t}+\theta \xi_{t}+\bar{\eta}_{\omega, t} \\
\Delta \bar{y}_{\omega, t} & =\gamma \zeta_{t}+\bar{\varepsilon}_{\omega, t}
\end{aligned}
$$

where $\bar{\eta}_{\omega, t}=\stackrel{\circ}{\mathbf{w}}^{\prime} \boldsymbol{\eta}_{t}$, and $\bar{\varepsilon}_{\omega, t}=\mathbf{w}^{\prime} \varepsilon_{t}$. Note now that $\operatorname{Var}\left(\bar{\varepsilon}_{\omega, t}\right)=\mathbf{w}^{\prime} \boldsymbol{\Sigma}_{\varepsilon \varepsilon} \mathbf{w} \leq\left(\mathbf{w}^{\prime} \mathbf{w}\right) \varrho_{\max }\left(\boldsymbol{\Sigma}_{\varepsilon \varepsilon}\right)$. Thus, under Assumptions (ii) and (iii), we have $\operatorname{Var}\left(\bar{\varepsilon}_{\omega, t}\right)=O\left(\mathbf{w}^{\prime} \mathbf{w}\right)=O\left(N^{-1}\right)$, and hence $\bar{\varepsilon}_{\omega, t}=$ $O_{p}\left(N^{-1 / 2}\right)$, where $O_{p}\left(N^{-1 / 2}\right)$ denotes stochastic boundedness. It follows that, under Assumptions (ii) and (iii), for $N$ sufficiently large, $\zeta_{t}$ can be identified (up to the scalar $1 / \gamma$ ) by $\bar{y}_{\omega, t}=\sum_{i=1}^{N} w_{i} \Delta y_{i t}$

\footnotetext{
${ }^{5}$ Formal econometric evidence supporting this assumption is provided by Kapetanios et al. (forthcoming).
} 
as:

$$
\zeta_{t}=\gamma^{-1} \Delta \bar{y}_{\omega, t}+O_{p}\left(N^{-1 / 2}\right)
$$

Note here that the fact that equity returns have at least one more common factor than growth rates, on its own, does not provide identification of the international business cycle shock. To get identification, we also need weak cross-country correlation and large $N$. This is because, with small $N$, we would not be able to disentangle $\zeta_{t}$ from $\bar{\varepsilon}_{\omega, t}$ (the average of $\varepsilon_{i t}$ in the equation for output growth above) and $\bar{\varepsilon}_{\omega, t}$ would remain a risk factor priced in the country specific equity returns.

Identifying the global financial factor follows a similar strategy. Under our assumptions, $\xi_{t}$ can be identified from the data as a linear combination of $\Delta \bar{y}_{\omega, t}$ and $\bar{r}_{\omega, t}$, up to an orthonormal transformation (as $N \rightarrow \infty$ ), given by:

$$
\xi_{t}=\theta^{-1}\left(\bar{r}_{\omega, t}-\frac{\lambda}{\gamma} \Delta \bar{y}_{\omega, t}\right)+O_{p}\left(N^{-1 / 2}\right)
$$

This result follows immediately from substituting (9) into (7) and applying the same reasoning as before.

\subsection{Identification and estimation of the common shocks in a dynamic setting}

Identifying the common shocks is considerably more complex in the heterogeneous dynamic setting given by Equations (1) and (2). As CPR show, however, observable proxies for $\zeta_{t}$ and $\xi_{t}$, can be obtained, under additional regularity conditions on the degree of heterogeneity and persistence in the country systems, by using a suitable pth-order truncated approximation of the the following infinite-order expressions for the unobservable factors:

$$
\begin{aligned}
& \zeta_{t}=b_{\zeta}+\gamma^{-1} \Delta \bar{y}_{\omega, t}+\sum_{\ell=1}^{\infty} \mathbf{c}_{\zeta, \ell^{\prime}}^{\prime} \overline{\mathbf{z}}_{\omega, t-\ell}+O_{p}\left(N^{-1 / 2}\right) \\
& \xi_{t}=b_{\xi}+\theta^{-1}\left(\bar{r}_{\omega, t}-\frac{\lambda}{\gamma} \Delta \bar{y}_{\omega, t}\right)+\sum_{\ell=1}^{\infty} \mathbf{c}_{\xi, \ell}^{\prime} \overline{\mathbf{z}}_{\omega, t-\ell}+O_{p}\left(N^{-1 / 2}\right)
\end{aligned}
$$

where $b_{\zeta}$ and $b_{\xi}$ are fixed constants, $\overline{\mathbf{z}}_{\omega, t}=\left(\bar{r}_{\omega, t}, \Delta \bar{y}_{\omega, t}\right), \mathbf{c}_{\zeta, \ell}^{\prime}$ and $\mathbf{c}_{\xi, \ell}^{\prime}$ are row vectors of coefficients resulting from the inversion of the matrix representation of the system (1)-(4). Augmenting the expressions (9) and (10) for the static case with higher order lags of $\left(\bar{r}_{\omega, t-\ell}, \Delta \bar{y}_{\omega, t-\ell}\right)$, for $\ell>1$, is necessary for consistent estimation to take account of dynamic heterogeneity on the identification 
of the unbearable common shocks that depend on lagged variables. In practice, the international business cycle shocks can be consistently estimated as residuals from the regression of global output growth on its lagged values as well as the lagged values of global equity returns, whilst global financial shocks are obtained as residuals from the regression of global equity returns on the estimated global growth shocks and the lagged values of global output growth and global equity returns.

As in the static case, $\zeta_{t}$ and $\xi_{t}$ can be identified only up to a non-singular transformation, which we take to be orthonormal, as it simplifies the computation and interpretation of impulse responses and error variance decompositions that we conduct later on in the paper. The latter is achieved by choosing coefficients in the linear regression of $\Delta \bar{y}_{\omega, t}$ on $p$ lags of $\overline{\mathbf{z}}_{\omega, t}$, and $\bar{r}_{\omega, t}$ on $\Delta \bar{y}_{\omega, t}$ and $p$ lags of $\overline{\mathbf{z}}_{\omega, t}$ such that the observable proxy for the common shocks have (in-sample) zero-means, unit variances, and, for a sufficiently high lag order $p$, will be serially uncorrelated. Note finally that one cannot arrive at these estimates by principal component (PC) analysis, where the common factors are estimated as PCs of output growth and/or equity return series considered separately or together, since the PC analysis does not make use of the a priori identification of the shocks and, being static in nature, cannot cope with the heterogeneous dynamics of the interactions between equity return and growth across countries.

\subsection{Alternative Identification Assumptions for Country-Specific Shocks}

In our model, the correlation between $\varepsilon_{i t}$ and $\eta_{i t}$ captures any contemporaneous causal relation between equity return and output growth at the country level, conditional on $\zeta_{t}$ and $\xi_{t}$. Thus far, we have not imposed any restrictions on these moments of the data for the purpose of identifying

the common shocks, only assuming that $\eta_{i t}$ and $\varepsilon_{i t}$, have zero means and finite variances, and are serially uncorrelated, but can be correlated with each other within countries and weakly correlated across countries, leaving the causal relation between the idiosyncratic shocks unrestricted.

In order to compute impulse responses to country-specific shocks and their importance in the variance decompositions that we report below, however, we need to deal with this second identification problem. To identify country-specific return and growth shocks we exploit the empirical properties of the estimated multi-country reduced form covariance matrix that we document in the next section, combined with alternative assumptions regarding the causal relation between equity returns and output growths innovations at the country-specific level. We then show that the inference 
we draw is reasonably robust to the alternative assumptions made.

Consider the complete covariance matrix of the multi-country model (1)-(4) for $i=1,2, \ldots, N$ and distinguish between off-diagonal covariance terms within each country block, and off-diagonal covariances terms between countries. In our baseline results reported in the next section, we allow for non-zero off block-diagonal elements between countries to account for their spillovers and factorize the within-country blocks with a Cholesky decomposition, ordering the equity returns first as a source of domestic financial shocks and thus assuming that country-specific equity returns shocks can have a contemporaneous causal impact on output growths but not vice versa. Before proceeding, however, we assess the statistical significance of the spillover elements by using the regularized multiple testing threshold estimator of Bailey, Pesaran, and Smith (2019), setting to zero all pairwise covariances statistically insignificant using suitably adjusted critical values. The list of statistically significant off-diagonal elements is reported in the appendix. ${ }^{6}$ Finally, we compute the generalized forecast error variance decompositions (GFVD) and impulse response functions (GIRF) of Pesaran and Shin (1998).

To check that our inference is robust, we also re-estimate the forecast error variance decompositions (FEVD) under alternative assumptions. We consider two polar cases. First, we assume that the estimated multi-country covariance matrix conditional on the estimated global factors shocks is truly diagonal, consistent with the empirical evidence reported in appendix that very few offdiagonal elements are significantly different from zero and no within block diagonal covariance term is statistically significant. This means assuming that our global growth shocks, statistically, explains 100 percent of the conditional correlation between country-specific equity returns and growth rates. Second, we leave this covariancce matrix completely unrestricted. As we shall see, the inference one can draw from the two alternative specifications of the multi-country error covariance matrix of country-specific shocks is essentially the same, except of course for the magnitude of the spillover effects from country-specific shocks which are larger the more off block-diagonal elements are allowed for.

The dynamic impacts and relative importance of all identified shocks can be obtained by substituting in (1)-(4) the estimated orthogonal factor innovations, $\hat{\zeta}_{t}$ and $\hat{\xi}_{t}$ based on the following

\footnotetext{
${ }^{6}$ This regularized estimator provides a consistent estimate of the multi-country error covariance matrix of the residuals of the multi-country model by exploiting its sparsity. See CPR for more details.
} 
regressions:

$$
\begin{aligned}
r_{i t}= & a_{i v}+\phi_{i, 11} r_{i, t-1}+\phi_{i, 12} \Delta y_{i, t-1}+\sum_{\ell=1}^{p} \mathbf{d}_{v, i \ell}^{\prime} \overline{\mathbf{z}}_{\omega, t-\ell} \\
& +\beta_{i, 11} \hat{\zeta}_{t}+\beta_{i, 12} \hat{\xi}_{t}+\eta_{i t}, \\
\Delta y_{i t}= & a_{i y}+\phi_{i, 21} r_{i, t-1}+\phi_{i, 22} \Delta y_{i, t-1}+\sum_{\ell=1}^{p} \mathbf{d}_{\Delta y, i \ell}^{\prime} \overline{\mathbf{z}}_{\omega, t-\ell} \\
& +\beta_{i, 21} \hat{\zeta}_{t}+\varepsilon_{i t}
\end{aligned}
$$

which can be estimated consistently by least squares so long as $N$ and $T$ are large enough. ${ }^{7}$ The multi-country PVAR model obtains by stacking the country-specific factor augmented VARs, (13)(14). The model is solved as explained in the online supplement to the CPR paper. The generalized variance decompositions and the impulse responses for the full multi-country model are then computed utilizing the CPR Matlab replication code.

\section{Data and stylized facts}

In this section we describe the data that we use in our empirical analysis and present some stylized facts on the cross country correlations of output growth and equity returns. The data set is a balanced panel of 32 advanced and emerging countries, from 1994:Q4 to 2016:Q4, for real GDP growth and stock market equity returns. ${ }^{8}$ The sample is cut at the beginning of 1994, as equity price data are not available earlier for some emerging economies, including Brazil and China. Better quality quarterly GDP data for China also are available only from 1993.

As a measure of economic activity, we use the log-difference of real GDP level, which we denote as $\Delta y_{i t}$. Similarly, we compute the stock market return for country $i$ in quarter $t$ as the log-difference of the the stock market index as:

$$
r_{i t}=\ln \left(P_{i t}\right)-\ln \left(P_{i t-1}\right)
$$

where $P_{i t}$ is the stock market index price observed at the end-of-quarter $t$ in country $i$. A battery of unit root tests show that both output growth rates and equity returns are stationary variables, as

\footnotetext{
${ }^{7}$ Large $N$ is required so that the probability order $O_{p}\left(N^{-1 / 2}\right)$ becomes negligible. Large $T$ is required to ensure that the dynamics are estimated accurately.

${ }^{8}$ See CPR on the data sources for quarterly real GDP and daily equity prices. The equity price indexes that we use are ex-dividend and in local currency. The list of countries is reported in the appendix.
} 
required by our analysis (results not reported).

The differential pattern of cross-country correlation among the output growth rates and equity returns is one way to motivate our identification strategy. So, the reminder of this section focuses on such patterns.

\subsection{Unconditional cross-country correlations}

We use pairwise correlation analysis in order to gauge the extent to which the time series of equity returns and output growths co-move across countries. The average pairwise correlation of country $i$ in the panel, $\bar{\rho}_{i}$, measures the average degree of co-movement of country $i$ with all other countries $j$, for all $j \neq i$. The average pairwise correlation across all countries, $\bar{\rho}_{N}$, is the cross-country average of $\bar{\rho}_{i}$ over $i=1,2, \ldots, N$. This statistics relates to the degree of pervasiveness or strength of the factors in a panel of time series. The attraction of the average pairwise correlation, $\bar{\rho}_{N}$, lies in the fact that it applies to multi-factor processes, and unlike factor analysis does not require the factors to be strong. In fact, $\bar{\rho}_{N}$ tends to a strictly positive number if the panel of time series is driven by at least one strong factor, otherwise it must tend to zero as $N \rightarrow \infty$. Therefore, non-zero estimates of $\bar{\rho}_{N}$ are suggestive of strong cross-sectional dependence, and indicate the presence of at least one strong factor. ${ }^{9}$

Figure 1 Average Pair-Wise Correlations: Equity Return $\left(r_{i t}\right)$ and Output Growth $\left(\Delta y_{i t}\right)$ Series

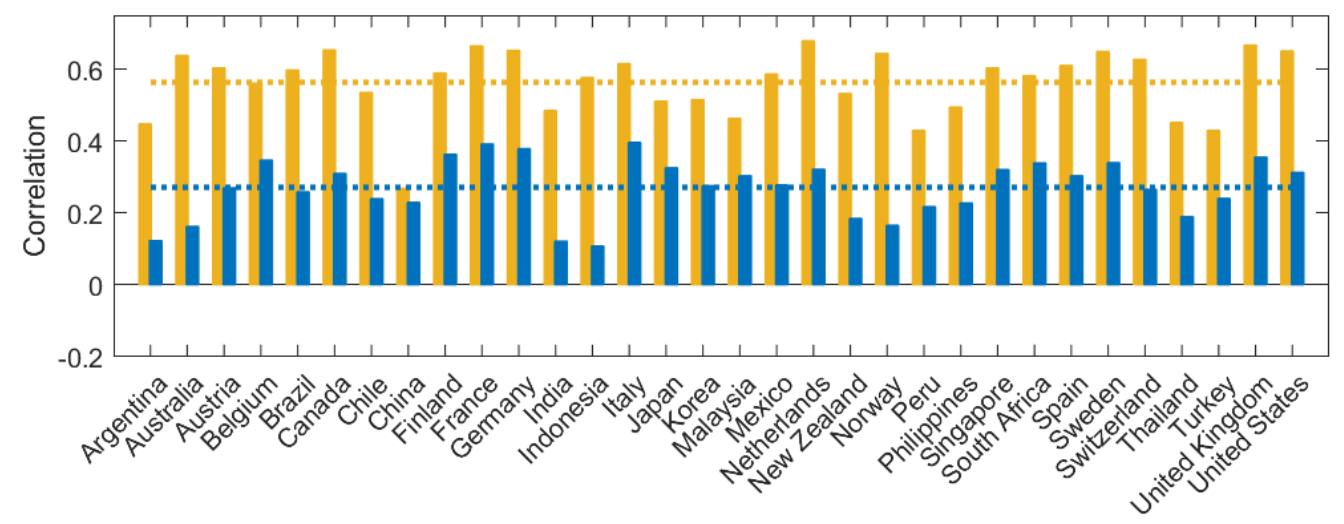

NoтE. For each country, the light (yellow) and the dark (blue) bar show the average pairwise correlation with the remaining countries in the sample, for equity return and GDP growth series, respectively $\left(\bar{\rho}_{i}\right)$. The dotted lines correspond to the overall average across all countries, equal to 0.56 and 0.27 , respectively $\left(\bar{\rho}_{N}\right)$. Sample period: 1994:Q4-2016:Q4.

\footnotetext{
${ }^{9}$ See Pesaran (2015) for more details and also formal tests of cross-sectional dependence based on estimates of $\bar{\rho}_{N}$.
} 
Figure 1 plots $\bar{\rho}_{i}$ for all $i=1,2, \ldots N$ and $\bar{\rho}_{N}$ for equity return and output growth series-light (yellow) and dark (blue) bars, respectively. The figure shows that the average across all countries of the pairwise correlation for the equity return series is more than twice the average for the growth series, at 0.56 and 0.27 , respectively (dotted lines). This evidence suggests that both series share at least one strong common factor, as we assumed for identification purposes, but the degree of crosscountry dependence shared among the equity return series is much stronger than among output growth series.

Comparing China and South Korea, we see that the two countries have an approximately equal pairwise output growth correlation, close to the overall average across countries, and consistent with their comparable degree of trade openness. However, Korea's pairwise equity return correlation is much higher than in China (0.52 and 0.27, respectively), consistent with a much lower degree of capital account openness and financial integration in this country.

\subsection{Conditional cross-country correlations}

Although the assumptions that we discussed above for the identification of the two common shocks cannot be formally tested, as the model is exactly identified, we can investigate the extent to which the moments of the data restricted by such assumptions are in line with the assumptions made. To this end, we can look at the degree of cross-country dependence of the estimated residuals or innovations from the dynamic regressions (13) and (14), with and without conditioning on the global financial shock, $\hat{\xi}_{t}$.

Consider first the hypothesis that both cross sections of output growths and equity returns are driven only by the international business cycle shock, $\hat{\zeta}_{t}$. We can then estimate the following countryspecific models for each country $i, i=1,2, \ldots, N$ :

$$
\begin{aligned}
r_{i t} & =\beta_{i, 11} \hat{\zeta}_{t}+\text { lagged cross-section averages and lagged endogenous values }+u_{i t} \\
\Delta y_{i t} & =\beta_{i, 21} \hat{\zeta}_{t}+\text { lagged cross-section averages and lagged endogenous values }+\varepsilon_{i t},
\end{aligned}
$$

where $u_{i t}$ is a residual capturing any cross-country dependence not captured by $\hat{\zeta}_{t}$.

Figure 2 shows that, if we condition only on the international business cycle shock $\hat{\zeta}_{t}$ in (13)(14), the equity return innovations display average pair-wise correlations pretty much like those in 
Figure 2 Average Pair-Wise Correlations of Equity Return $\left(u_{i t}\right)$ And Growth Rate $\left(\varepsilon_{i t}\right)$ Innovations Conditional on $\hat{\zeta}_{t}$

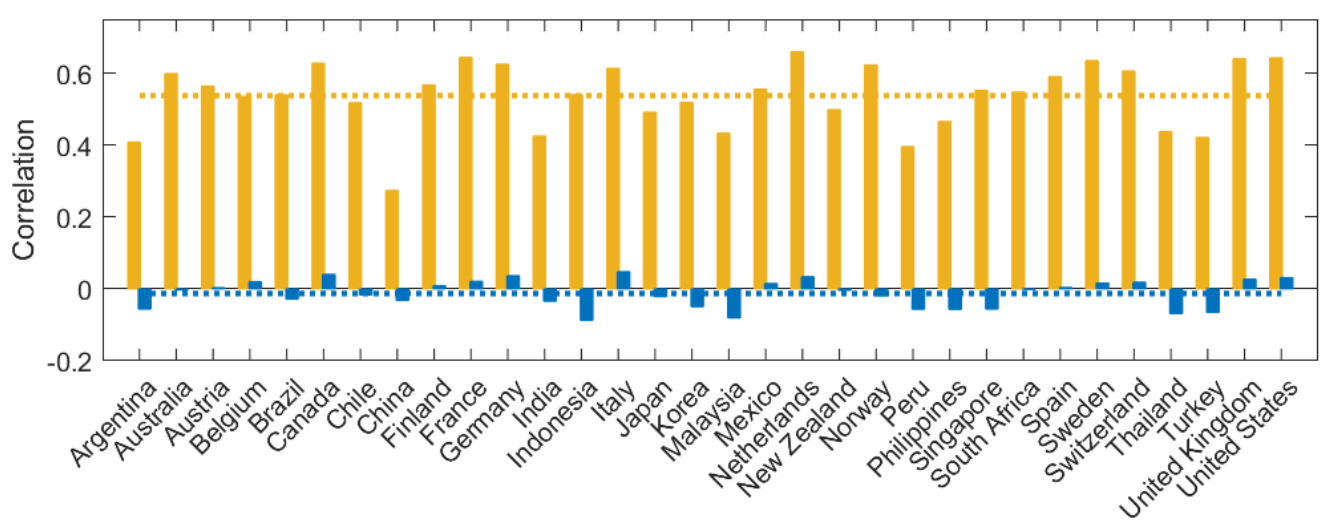

Noте. For each country, the light (yellow) and the dark (blue) bar show the average pairwise correlation with the remaining countries in the sample for the estimated equity return and GDP growth innovations conditional on $\hat{\zeta}_{t}$ only. The dotted lines correspond to the overall average across all countries, equal to 0.54 and -0.01, respectively. Sample period: 1994:Q42016:Q4.

the raw data, reported in Figure 1. In contrast, the pairwise correlations of the estimated growth innovations is negligible with this conditioning, with an average across all countries of -0.01 . This evidence clearly suggests that, consistent with the identification assumptions made, one common factor is sufficient to capture the cross-country dependence of the output growth series, while the equity return series share at least one more strong factor.

Consider now country-specific models conditional on both the international business cycle shock, $\hat{\zeta}_{t}$, and the global financial cycle shock, $\hat{\xi}_{t}$, for all $i$ with $i=1,2, \ldots N$ :

$$
\begin{aligned}
r_{i t} & =\beta_{i, 11} \hat{\zeta}_{t}+\beta_{i, 12} \hat{\xi}_{t}+\text { lagged cross-section averages and lagged endogenous values }+\eta_{i t}, \\
\Delta y_{i t} & =\beta_{i, 21} \hat{\zeta}_{t}+\text { lagged cross-section averages and lagged endogenous values }+\varepsilon_{i t}
\end{aligned}
$$

Figure 3 shows that, if we condition on both $\hat{\zeta}_{t}$ and $\hat{\xi}_{t}$, then the cross-country correlations of the equity return innovations also become negligible, as in the case of the growth innovations, with an average pair-wise correlation across all countries equal to -0.02 . For example, in the specific case of the United States, which is the most important equity market in world, the average pair-wise correlation of the return innovations is equal to 0.64 conditioning on $\hat{\zeta}_{t}$ alone. But the correlation drops to 0.05 if we condition on both common shocks. By comparison, the U.S. average pair-wise correlation of the growth innovations is 0.03. Similarly, in the case of Korea and China, the pairwise 
Figure 3 Average Pair-Wise Correlations of Equity Return $\left(\eta_{i t}\right)$ and Growth $\operatorname{Rate}\left(\varepsilon_{i t}\right)$ Innovations Conditional on $\hat{\zeta}_{t}$ And $\hat{\xi}_{t}$

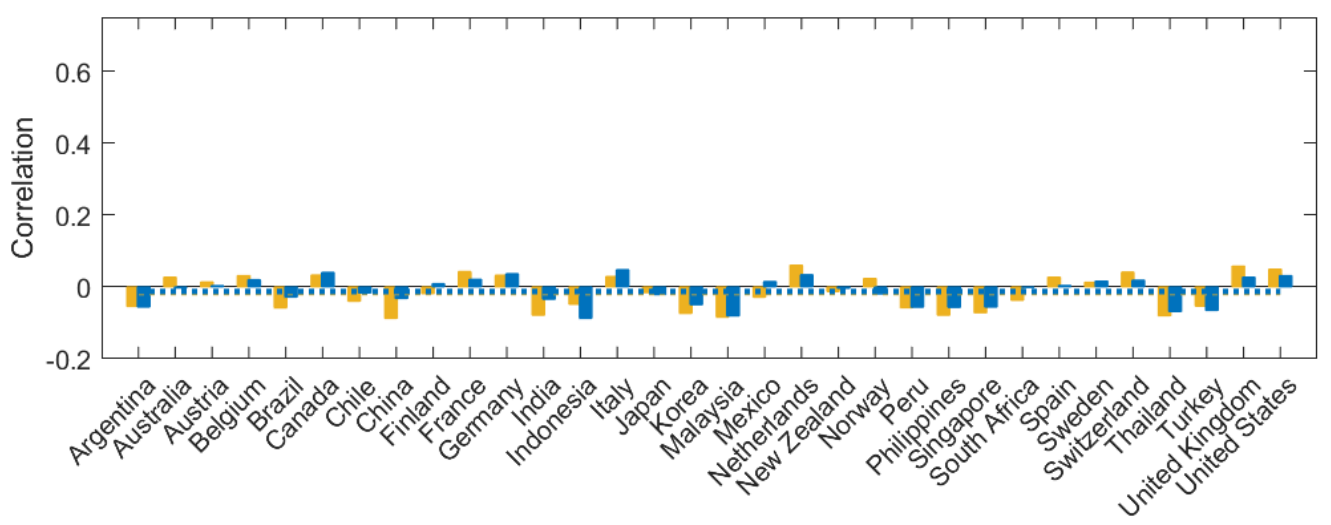

Note. For each country, the light (yellow) and the dark (blue) bar show the average pairwise correlation with the remaining countries in the sample for equity return and GDP growth innovations, conditional on $\hat{\zeta}_{t}$ and $\hat{\xi}_{t}$. The dotted lines correspond to the overall average across all countries, equal to -0.02 and -0.01 , respectively. Sample period: 1994:Q4-2016:Q4.

correlation of the equity returns drop from 0.52 and 0.27 , to -0.07 and -0.09 , respectively, when we condition on both global factor innovations.

These results thus indicate that our two common shocks are sufficient to span the cross-country dependence in both the panel of output growths and equity returns as we assumed in our theoretical model. ${ }^{10}$ Even at the level of individual pairwise correlations, the results of the Bailey et al. (2019) regularized multiple testing threshold estimation procedure show that of the 2032 covariance terms, only 68 off-diagonal elements are significantly different from zero and no within-country block covariance element is statistically significant. As we noted earlier, the empirical properties of the estimated multi-country covariance matrix greatly simplify the task to identify country-specific shocks. This further implies that, effectively, the variable order within the country blocks factorized with the Cholesky decomposition does not matter. To conserve space, therefore, in the next section, we do not report this alternative set of results.

\section{Empirical results}

In this section we report our empirical results. We discuss first the estimates of the international business cycle and global financial shocks. Next, we evaluate their relative importance in driving

\footnotetext{
${ }^{10}$ It is important to stress, here that, as CPR discuss at length, the same results would not obtain inverting the conditioning order-i.e., conditioning first on $\hat{\xi}_{t}$ and then on $\hat{\zeta}_{t}$.
} 
country-specific equity returns and output growth rates in South Korea, China and the average economy in our sample. We then provide some intuition for the main results.

\subsection{International Business Cycle and Global Financial Shocks}

Figure 4 plots the estimated international business, $\hat{\zeta}_{t}$, and global financial shocks, $\hat{\xi}_{t}$, together with a one-standard error band. These shocks have zero means and unit in-sample variances. They are also serially uncorrelated and orthogonal to each other by construction, as we discussed above.

Looking first at the international business cycle shock in Panel A, we can see that the two largest negative realizations were during the Asian crisis in 1997 and the global financial crisis in 2008, consistent with prevailing narratives on the characterization of the international business cycle during the period considered. The estimated shocks are otherwise well inside the one-standard error.

Figure 4 Estimated International Business Cycle and Global Financial Cycle SHOCKS
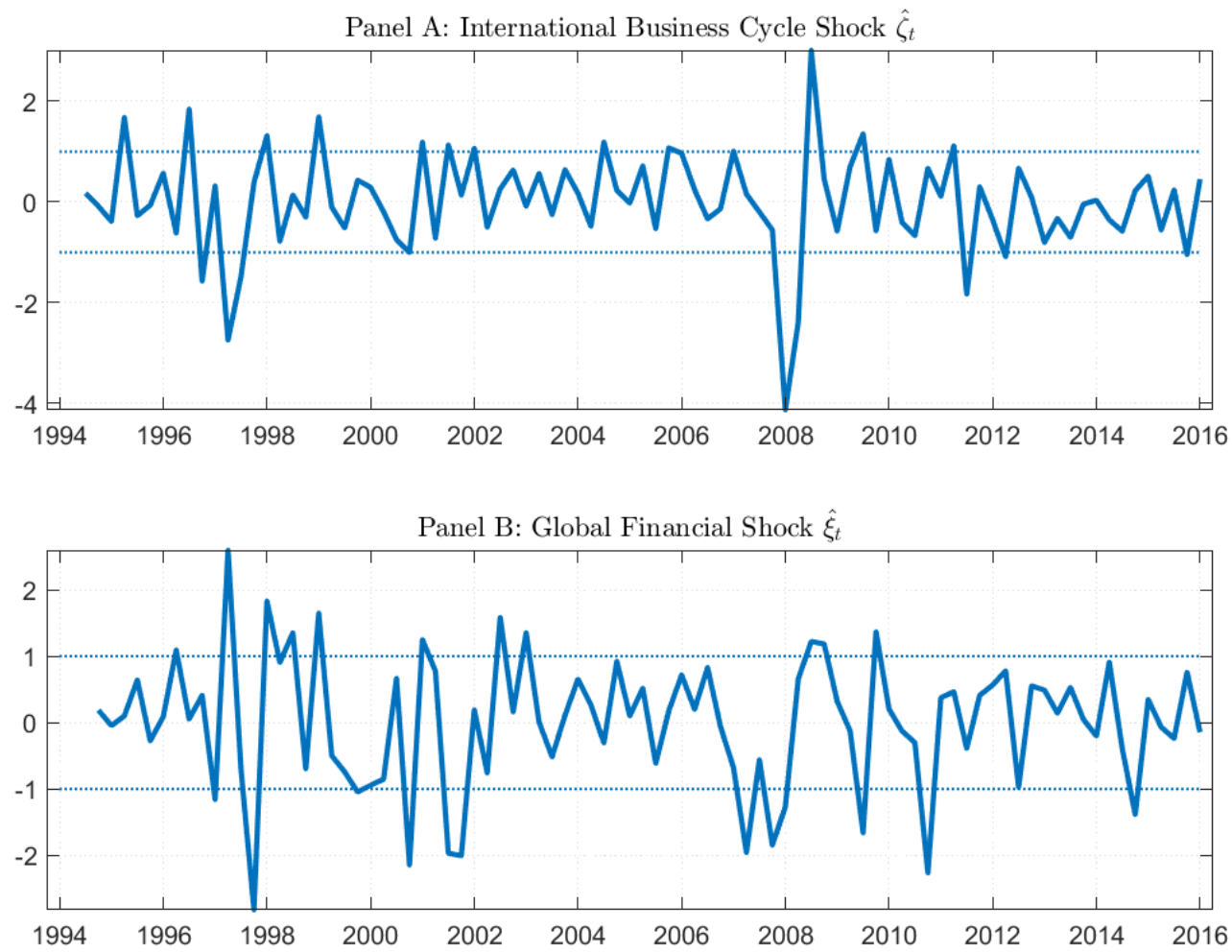

Note. The global shocks $\hat{\zeta}_{t}$ and $\hat{\xi}_{t}$ are computed using (11) and (12), truncated at lag one of $\mathbf{z}_{i t}$, using a balanced sample 1994:Q1-2016:Q4. The shocks are standardized, and the dotted lines are the one-standard deviation bands around the zero mean. 
Figure 5 Estimated Global Financial Factor
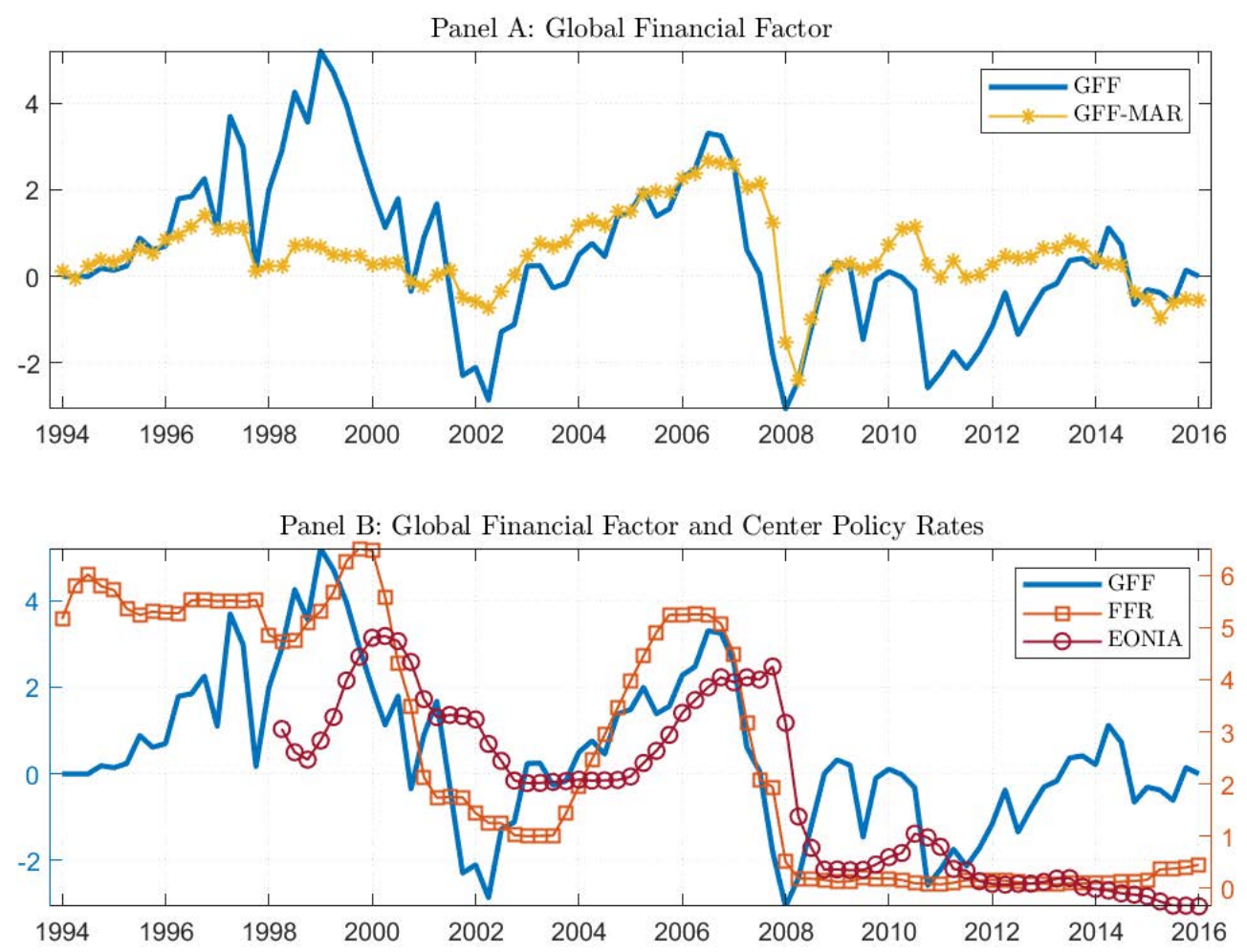

Note. Panel A plots the cumulative sum of our global financial shock $\sum_{s=0}^{t} \hat{\xi}_{s}$ together with a quarterly average of an updated estimate of the Global Factor from Miranda-Agrippino and Rey (2020). Panel B plots the cumulative sum of our global financial shock $\sum_{s=0}^{t} \hat{\xi}_{s}$ (left axis) together with a quarterly average of the U.S. Federal Funds rate and the ECB Eonia rate (right axis). Sample period: 1994:Q4-2016:Q4.

The estimated international business cycle shock, once aggregated at annual frequency, correlates very closely with alternative measures of global TFP growth. For example, the correlation with the global utilization-adjusted TFP growth estimate of Huo, Levchenko, and Pandalai-Nayar (2018) is 0.59 for the sample period over which the two measures overlap through 2007, increasing to 0.83 when we consider their unadjusted measure. The estimated shock is also highly correlated with the TFP growth in advanced economies from The Conference Board Total Economy Database, with a correlation of 0.52. This evidence supports an interpretation of $\hat{\zeta}_{t}$ as a technology factor, even though this common shock could also capture other world demand or supply factors, as highlighted by the difference between the correlations with the adjusted and unadjusted global TFP growth.

Consider now the the estimated global financial cycle shocks in Panel B of Figure 4. The largest shock realizations coincide with the boom-bust period of the Asian crisis in 1997, the U.S. dotcom 
equity bubble, the global financial crisis in 2008 and the European crisis in 2011. Most other realizations are inside the one-standard error band or within two deviations.

To help evaluating the estimation results, Figure 5 plots the cumulative realization of the estimated global financial shock (GFF). Panel A in figure 5 compares our measure to an updated estimate of the Global Financial Factor in risky asset prices from Miranda-Agrippino and Rey (2020) (GFFMAR). As we can see, the two estimates are remarkably close, with a correlation of 0.55. Our estimate is more volatile, but seemingly better capturing the U.S. dot-com equity price bubble of the late 1990s and the subsequent period global financial exuberance. Particularly notable is the close tracking of the European crisis in 2010-11 and subsequent recovery in global financial conditions triggered by the unconventional monetary policies of the major advanced economy central banks. Indeed, Panel B of Figure 5 plots our proxy for the GFC together with the U.S. Federal Fund Rate and the ECB Eonia rate, crude measures of the monetary policy stance in center economies, showing that our measure co-moves closely with policy rates, with correlations of more than 0.7 and 0.4 , respectively.

Equipped with these estimated international business cycle and global financial shocks, we can now proceed to evaluate their relative importance for country-specific equity returns and output growths in South Korea, China as well as the average economy in our sample.

\subsection{Sizing the Global Financial Cycle}

Our factor augmented multi-country PVAR model can be used to decompose the forecast error variance of country-specific equity returns and output growths. In particular, we can assess the relative importance of the two global shocks that we identified, $\hat{\zeta}_{t}$ and $\hat{\xi}_{t}$, as well as the $64 \times 1$ vector of country-specific shocks, $\hat{\eta}_{i t}$ and $\hat{\varepsilon}_{i t}$, for $i=1,2, \ldots ., 32$, which represent idiosyncratic domestic shocks and spillover from such shocks in all other countries in the sample.

The baseline results reported here are based on (13)-(14), conditional on both $\hat{\zeta}_{t}$ and $\hat{\xi}_{t}$. As we noted earlier, the two common shocks, $\hat{\zeta}_{t}$ and $\hat{\xi}_{t}$, are orthogonal to each other and to all countryspecific shocks. Consistent with the evidence in Figure 3 and Appendix Table 2, the estimated covariance matrix of the $64 \times 1$ vector of country-specific shocks, $\hat{\eta}_{i t}$ and $\hat{\varepsilon}_{i t}$ for $i=1,2, \ldots ., 32$, is nearly diagonal with very few off-diagonal elements statistically different from zero. ${ }^{11}$ In order to evaluate

\footnotetext{
${ }^{11}$ As we can see from Appendix Table 2, of the 2032 covariance terms, only 68 are significantly different from zero, statistically, or about $3.3 \%$ of the total. Moreover, none of these elements are within-country covariance terms between
} 
Figure 6 Generalized Forecast Error Variance Decomposition of Country-Specific EQUITY RETURNS
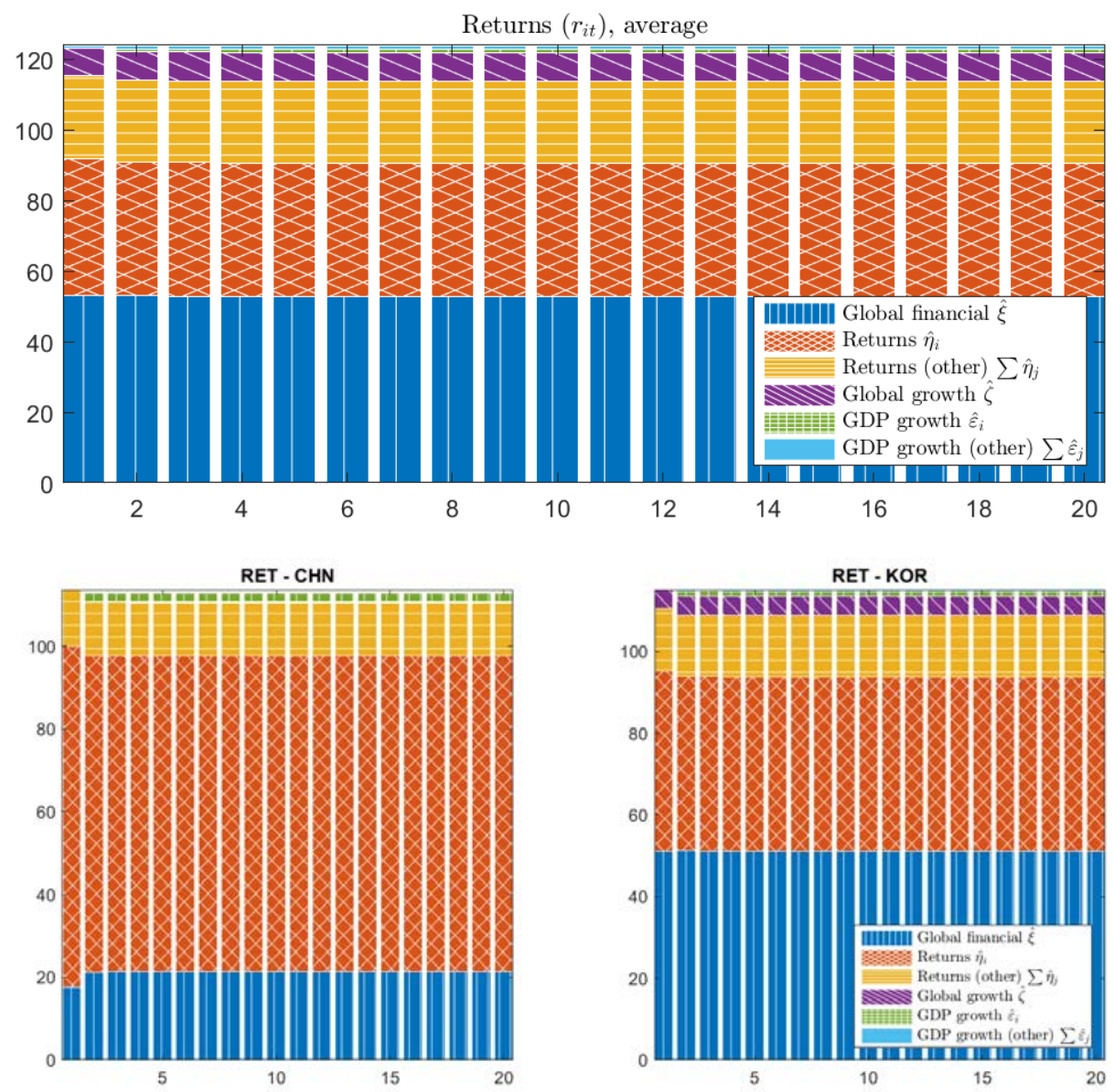

Nоте. In this figure, the blue area with vertical lines is the global financial shock, $\hat{\xi}$; the red area with crosses is the countryspecific financial shock, $\hat{\eta}_{i}$; the yellow area with horizontal lines is the spillover effect, given by the sum of the contributions of the country-specific financial shocks in all other countries in the sample, denoted $\sum \hat{\eta}_{j}$; the purple area with diagonal lines is international business cycle shock, $\hat{\zeta}$; the green areas with squares is the country-specific GDP growth shock, $\hat{\varepsilon}_{i}$; and the light blue areas with no pattern is the sum of the contributions of the GDP growth shocks in the other countries i the sample, denoted $\sum \hat{\varepsilon}_{j}$. The vertical axis is in percent, the horizontal axis is in quarters. The top panel reports results for the GDP-PPP weighted average GFVD across all countries in the sample. The left-bottom panel reports results for China. The right-bottom panel reports results for South Korea. Sample period: 1994:Q1-2016:Q4. Note that the GFVDs need not add up to 100 percent as the underlying shocks are not orthogonal due to the presence of few off-diagonal non-zero elements.

the importance of the spillover effects of such non-zero elements, we use the generalized forecast error variance decompositions (GFVD) of (Pesaran and Shin (1998)), which do not necessarily add up to 100 percent because of the off block-diagonal non-zero elements.

Figure 6 plots the average GFVD decomposition of equity returns across all countries in our sample, as well as the decomposition for China and South Korea. The figure shows that the global

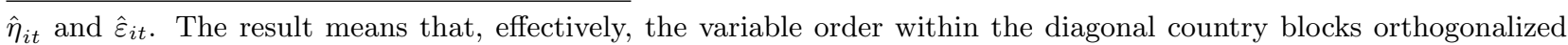
with the Cholesky decomposition does not matter. 
financial cycle shock, $\hat{\xi}_{t}$, explains more than 50 percent of the country-specific equity return variance in the average economy in our sample. In Korea, shocks to the global financial factor account for a similar share as in the average economy. In contrast, in China, the most important driver of the equity return variance is the idiosyncratic equity return shock itself, $\hat{\eta}_{i t}$, even though the global financial factor shock still accounts for more than 20 percent of the equity return variance. In both countries, common and idiosyncratic shocks to output growth $\left(\hat{\zeta}_{t}\right.$ and $\hat{\varepsilon}_{i t}$, respectively), the fundamentals of the country-equity market in our simple model, play a negligible role in accounting for return variability, in line with the results for the average economy, and consistent with the typical findings in the asset pricing literature. Spillovers from financial shocks originating in other countries in our sample, $\sum \hat{\eta}_{j}$, play a sizable but secondary role in both Korea and in China, in a manner comparable to the average economy. Spillovers from output growth shocks originating in other countries are similarly negligible in all countries.

These baseline results are consistent with the Global Financial Cycle hypothesis of Rey (2013), which states that a single common factor drives a large portion of the international co-movement in asset prices. As Cerutti et al. (2017) also found, however, it is evident that the global financial cycle is not the only determinant of country-specific equity returns. Idiosyncratic financial shocks and, to a lesser extent, spillovers from such country-specific shocks in other countries also play a quantitatively important role. The different results for Korea and China, in particular, are consistent with the notion that a more open capital capital account, as in the case of South Korea, is associated with a higher exposure to the global financial cycle. A closer capital account, in contrast, comes about with a much larger role for domestic financial shocks, consistent with a standard diversification argument in favor of capital account openness, but cannot completely insulate the domestic equity market from the global financial cycle.

As Figures 9 and 11 in the appendix illustrate, these baseline results are robust to using alternative assumptions on the multi-country covariance matrix of the country-specific shocks. Figure 9 assumes that the multi-country covariance matrix is diagonal, while Figure 11 assumes that it is unrestricted. What changes across the different specifications is the size of the estimated spillover effects that depend on the off block-diagonal elements of multi-country covariance matrix. The variance shares of the common and idiosyncratic shocks, however, are pretty comparable across alternative specifications, which leads us to draw the same conclusions. 
Figure 7 Generalized Forecast Error Variance Decomposition of Country-Specific Output Growths
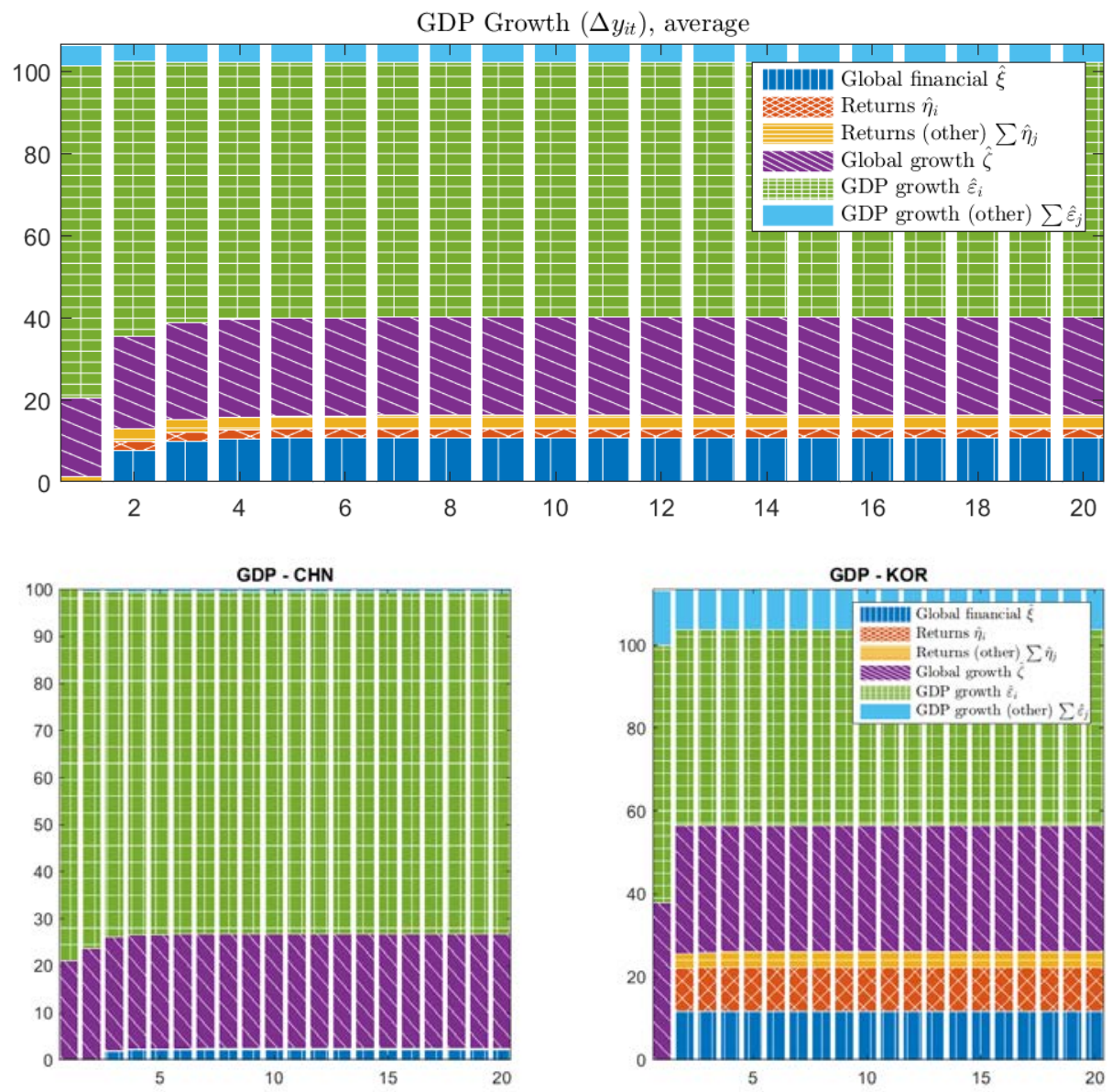

Note. See Figure 6.

\subsection{South Korea and China Exposure to Global and Country-Specific Financial Shocks}

We have seen in the previous section that the global financial cycle is an important driver of countryspecific equity returns, even in China where the capital account of the balance of payment was relatively closed over the sample period. In this section, we want to explore the importance of this common factor for the domestic business cycle.

Figure 7 reports the GFVD of country-specific quarterly output growth rates. The figure shows that global financial shocks, $\hat{\xi}_{t}$, explain about 10 percent of growth variance, on average, across all countries in our sample; a non-negligible but not conspicuous contribution. This result clearly shows that even if global financial shocks are very important drivers of equity returns globally, they have 
a much smaller role in driving the business cycle of these economies, with a much larger role for domestic factors.

Korea business cycle turns out to be as exposed to global financial cycle shocks as the average economy in our sample, while China appears significantly less exposed according to these estimates, with a tiny variance share accounted for by the global financial shock. The finding suggests that even if a closed capital account cannot completely insulate the domestic stock market from the influences of the global financial cycle, perhaps because of information channel of transmission of news and sentiment changes that cannot be easily halted at the border, it can go a long way toward shielding the economy from its real consequences.

Consistent with their high degree of trade openness, both countries are more exposed to international business cycle shocks, $\hat{\zeta}_{t}$, than the average economy in the sample. Their share of output growth variance explained by the international business cycle shock is more than 20 percent, at least twice the relative importance of the global financial cycle shock.

A surprising difference between China and South Korea is the fact that not only spillovers from other countries' idiosyncratic shocks, both financial and real in nature $\left(\sum \hat{\eta}_{j}\right.$ and $\sum \hat{\varepsilon}_{j}$, respectively), but also domestic financial shocks, $\hat{\eta}_{j}$, have some explanatory power for output fluctuations in Korea, with a GFVD share that is much larger than in the average economy in the sample, and comparable to the importance of the global financial cycle shock. In the case of China, in contrast, domestic financial shocks have essentially no explanatory power, like in the average economy in the sample.

This latter result is puzzling, as a standard diversification argument about the benefits and costs of capital account openness, would suggest that domestic financial shocks should be more important in the less diversified economy. A first hypothesis is that this is a reflection of the incomplete insulation properties of a floating exchange rate regime that accompany the relatively open capital account in Korea, consistent with the GFC hypothesis as originally formulated by Rey (2013) and the framework proposed by Gourinchas (2018). An alternative interpretation, consistent with the extant literature on the elusive benefits of capital account liberalization (or lack thereof), is that these benefits are not tangible, in the sense that they do not materialize in terms of higher (or less volatile) real GDP growth and are difficult to detect in macroeconomic data analyses. ${ }^{12}$

A second striking difference between the two countries is that idiosyncratic growth shocks, $\hat{\varepsilon}_{j}$,

\footnotetext{
${ }^{12}$ See, for example, Erten, Korinek, and Ocampo (forthcoming) for a discussion.
} 
are estimated to account for more than 70 percent of China's output growth variance, dwarfing the importance of all other shocks in the model for China's business cycle. In contrast, in Korea, idiosyncratic growth shocks explain a share of output growth variance that is even smaller than in the average economy in the sample. Thus, it is possible that the country-specific growth shock picks up some of the non-diversified risk of the domestic equity return shock. In other words, it is also possible that the loss of diversification opportunities theoretically associated with a closed capital account, in China, is reflected in the very large role attributed to the domestic business cycle shock, thus providing a third possible interpretation of the puzzling result reported above.

As in the case of the equity return variance decompositions, the baseline results reported in Figure 7 are robust to using alternative identification assumptions for the factorization of the multi-country covariance matrix of the idiosyncratic shocks (Figures 10 and 12).

\subsection{China and South Korea: Further Evidence on the Different Exposure to Idiosyncratic Financial Shocks}

The different exposure of China and South Korea to global and country specific financial shocks can be further illustrated by looking at impulse response functions to such shocks. Figure 8 compares the impulse responses of country-specific equity returns (Panels A and C) and GDP growths (Panels B and D) to our global (Panels A and B, $\hat{\xi}_{t}$ ) and idiosyncratic (Panels C and D, $\hat{\eta}_{j}$ ) financial shocks. The figure plots the responses of China (dashed, red line with circles), South Korea (dashed, blue line with squares), and a PPP-GDP weighted average of all countries in the sample (solid, black line). The shaded areas represent a two-standard-deviation error band around the average response in the sample, based on the dispersion of the impulse responses across countries computed as discussed by CPR. Recall here that the global financial shock is orthogonal to the international business cycle shock, by construction. The country specific financial shock is identified with a Cholesky decomposition of the reduced form variance-covariance matrix, ordering the country-specific equity return first within the each country block. We focus on the effects of positive one-standard deviation shocks.

The impulse responses suggest that the lower (higher) exposure of China (South Korea) to the global financial cycle that we documented above may come about at the cost (with the benefit) of reduced (increased) financial diversification opportunities for investors in the Chinese (Korean) stock 
Figure 8 Impulse Responses of Country-Specific GDP Growths And Equity Returns to Global and Idiosyncratic Financial Shocks

(A) Returns response to $\xi_{t}$

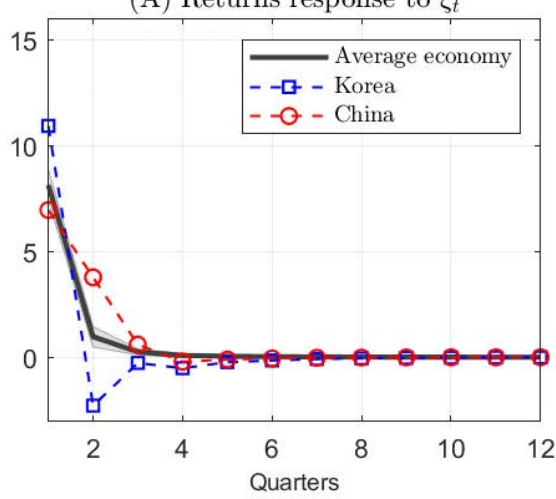

(C) Returns response to $\eta_{i t}$

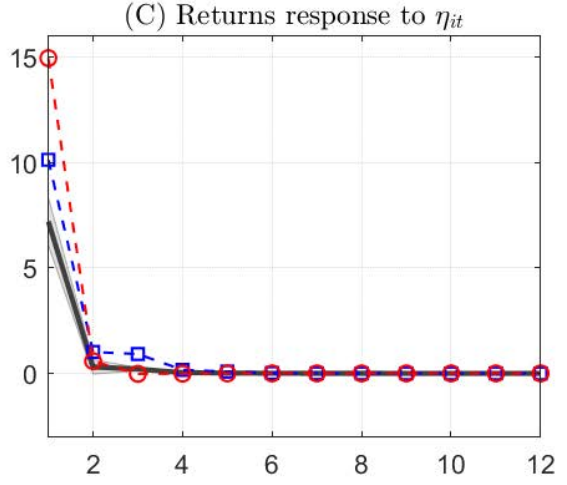

(B) GDP growth response to $\xi_{t}$

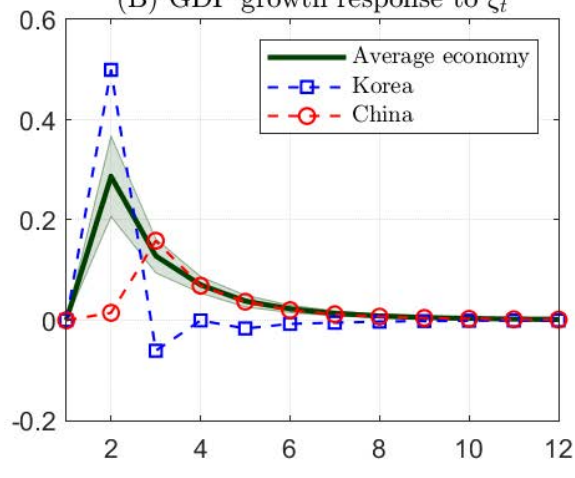

(D) GDP growth response to $\eta_{\text {it }}$

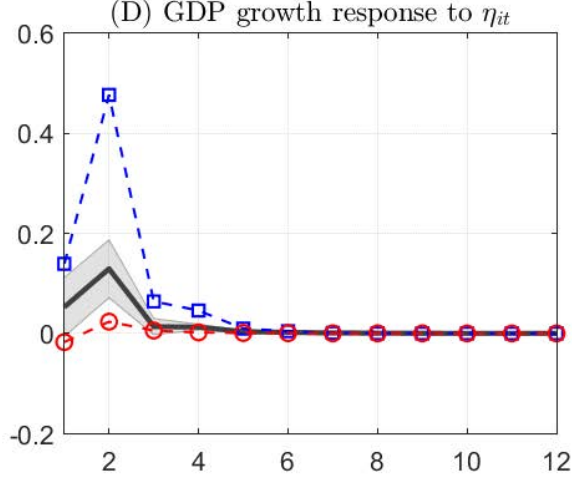

Note. The figure plots the responses of China (dashed, red lines with circles), South Korea (dashed, blue lines with squares), and a weighted average of all countries in the sample (solid, black lines), with PPP-GDP weights. The vertical axis is in percent, the horizontal axis is in quarters. Sample period: 1994:Q4-2016:Q4.

market. The better financial diversification opportunities of South Korea, however, do not translate into a higher degree of insulation of Korean output from idiosyncratic financial shocks.

Panels A and B show that the responses of the Korean equity return to the global financial shock is about 30 percent larger than the Chinese one, leading also to a much larger and more volatile response of output growth to this shock. The converse, however, hold only partially with respect to country specific financial shocks. Indeed, Panel $\mathrm{C}$ and $\mathrm{D}$ show that while equity returns in China are 30 percent more sensitive to domestic financial shocks, this does not translates into a higher sensitivity of domestic output to such shocks. On the contrary, as we can see from Panel D, Korea shows a very strong lagged output response to the domestic financial shock and a contemporaneous response that is higher than in China, but still on the edge of the error band for the average in the 
sample.

The time profile of the Korean output response to the global financial shock, with an above average increase one quarter after the shock and below sample average responses for up to two years after the shock, could be interpreted in terms of the boom-bust cycle in capital flows during the Asian crisis at the beginning of the sample period, which was amplified by large foreign exchange balance sheet exposures. However, the output response to the domestic financial shock is more difficult to interpret. Here, we only notice that Korea has a relatively large domestic financial sector that developed and was liberalized progressively after the Asian financial crisis, with foreign exchange exposures in the corporate sector balance sheet that could weaken the insulation properties of a floating exchange rate. China, in contrast, started this process much later and more slowly. More generally, as we discussed earlier, while a deeper structural interpretation of these empirical findings is beyond the scope of this paper, the evidence is consistent with a large body of empirical evidence finding limited benefit from capital account liberalization and some insulating power of capital controls.

\section{Conclusions}

This paper evaluates the global financial cycle (GFC) hypothesis and compares the insulating properties of two different capital account regimes in China and South Korea. We exploit the different cross-country correlation structure of equity returns and output growth innovations to identify an international business cycle shock and a global financial factor shock, and use conventional assumptions to identify idiosyncratic shocks. We then compare two countries, China and South Korea, with a closed capital account and fixed exchange rate regime and open capital account with floating exchange rate, respectively.

We find evidence of a conspicuous global financial cycle in equity market returns, with Korea behaving as the average economy in the sample, and China being relatively less exposed. Global financial shocks, however, are not quantitatively as important as common and country-specific business cycle shocks, or spillovers from other countries' idiosyncratic shocks in driving the business cycle of both countries. In the case of Korea, in particular, we find that global financial shocks explain about 10 percent of the business cycle volatility.

The empirical results can be partially interpreted in terms of higher diversification opportunities offered by capital account openness at the cost of a larger exposure to the global financial factor. 
The experience of China, however, suggests that no country can insulate completely from the global financial cycle, while the case of Korea is in line with a large body of empirical evidence suggesting that the benefits of capital account liberalization might be more elusive than the theory suggests and growing evidence that floating exchange rates might not as effective as insulating policy tools as traditionally assumed. 


\section{References}

BAI, J. AND S. NG (2002): "Determining the Number of Factors in Approximate Factor Models," Econometrica, 70, 191-221.

Bai, Y., F. Perri, And P. Kehoe (2019): "World financial cycles," 2019 Meeting Papers 1545, Society for Economic Dynamics.

Bailey, N., M. H. Pesaran, And L. V. Smith (2019): "A multiple testing approach to the regularisation of large sample correlation matrices," Journal of Econometrics, 208, 507-534.

Cerutti, E., S. Claessens, and A. K. Rose (2017): "How Important is the Global Financial Cycle? Evidence from Capital Flows," NBER Working Papers 23699, National Bureau of Economic Research, Inc.

Cesa-Bianchi, A., L. F. Cespedes, and A. Rebucci (2015): "Global liquidity, house prices, and the macroeconomy: Evidence from advanced and emerging economies," Journal of Money, Credit and Banking, 47, 301-335.

Cesa-Bianchi, A., A. Ferrero, And A. Rebucci (2018): "International credit supply shocks," Journal of International Economics, 112, 219-237.

Cesa-Bianchi, A., M. H. Pesaran, And A. Rebucci (2019): "Uncertainty and Economic Activity: A Multicountry Perspective," The Review of Financial Studies, 33, 3393-3445.

Chamberlain, G. and M. Rothschild (1982): "Arbitrage, Factor Structure, and Mean-Variance Analysis on Large Asset Markets," Scholarly Articles 3230355, Harvard University Department of Economics.

Chudik, A., M. H. Pesaran, and E. Tosetti (2011): "Weak and strong cross-section dependence and estimation of large panels," Econometrics Journal, 14, C45-C90.

Colacito, R. And M. M. Croce (2011): "Risks for the Long Run and the Real Exchange Rate," Journal of Political Economy, 119, 153-181.

Engel, C. (2016): "Macroprudential Policy under High Capital Mobility: Policy Implications from an Academic Perspective," Journal of the Japanese and International Economies, 42, 162-172.

Erten, B., A. Korinek, And J. A. Ocampo (forthcoming): "Capital Controls: Theory and Evidence," Journal of Economic Literature.

Gourinchas, P.-O. (2018): "Monetary Policy Transmission in Emerging Markets: An Application to Chile," in Monetary Policy and Global Spillovers: Mechanisms, Effects and Policy Measures, ed. by E. G. Mendoza, E. Pastén, and D. Saravia, Central Bank of Chile, vol. 25, chap. 08, 279-324, 1 ed.

Ha, J., M. A. Kose, C. Otrok, and E. S. Prasad (2020): "Global Macro-Financial Cycles and Spillovers," Working Paper 26798, National Bureau of Economic Research.

Han, X. AND S.-J. Wei (2018): "International Transmissions of Monetary Shocks: Between a Trilemma and a Dilemma," Journal of International Economics, 110, 205-219.

Huo, Z., A. Levchenko, And N. Pandalai-Nayar (2018): "Technology and Non-Technology Shocks: Measurement and Implications for International Comovement," Unpublished manuscript.

Kapetanios, G., M. H. Pesaran, and S. Reese (forthcoming): "Detection of units with pervasive effects in large panel data models," Journal of Econometrics.

LEwIS, K. K. AND E. X. LIU (2015): "Evaluating international consumption risk sharing gains: An asset return view," Journal of Monetary Economics, 71, 84-98.

Lucas, Robert E, J. (1978): "Asset Prices in an Exchange Economy," Econometrica, 46, 14291445.

Ma, C., J. Rogers, And S. Zhou (2019): "The Effect of the China Connect," Manuscript.

Miranda-Agrippino, S. And H. Rey (2020): "U.S. Monetary Policy and the Global Financial Cycle," The Review of Economic Studies, rdaa019.

Pesaran, H. H. And Y. Shin (1998): "Generalized impulse response analysis in linear multivariate 
models," Economics Letters, 58, 17-29.

Pesaran, M. H. (2015): Time Series and Panel Data Econometrics, Oxford University Press, Oxford.

Rebucci, A. And C. Ma (2020): "Capital Controls: A Survey of the New Literature," .

REY, H. (2013): "Dilemma not trilemma: the global cycle and monetary policy independence," Proceedings - Economic Policy Symposium - Jackson Hole, 1-2.

Ross, S. A. (1976): "The arbitrage theory of capital asset pricing," Journal of Economic Theory, $13,341-360$.

Sentana, E. (2002): "Did the EMS Reduce the Cost of Capital?" Economic Journal, 112, 786-809.

TESAR, L. L. (1995): "Evaluating the gains from international risk sharing," Carnegie-Rochester Conference Series on Public Policy, 42, 95-143.

ZeEv, N. B. (2017): "Capital Controls as Shock Absorbers," Journal of International Economics, 109, 43-67. 


\section{A Additional Tables}

Table 1 List of Countries

\begin{tabular}{|c|c|c|c|}
\hline ARGENTINA & FINLAND & MALAYSIA & South Africa \\
\hline Australia & FRANCE & MeXICO & SpAIN \\
\hline Austria & Germany & NetherLANDS & SWEDEN \\
\hline BELGIUM & INDIA & New Zealand & SWITZERLAND \\
\hline BRAZIL & INDONESIA & NORWAY & Thailand \\
\hline CANADA & ITALY & PERU & TURKEY \\
\hline ChILE & JAPAN & Philippines & United KINGDOM \\
\hline China & KoreA & SINGAPORE & United States \\
\hline
\end{tabular}


Table 2 Non-Zero Elements of the Regularized Error Covariance Matrix Estimate

\begin{tabular}{|c|c|c|c|c|c|}
\hline \multicolumn{3}{|c|}{ All Significant } & \multicolumn{3}{|c|}{ Between-county correlations } \\
\hline \multicolumn{2}{|c|}{ Country - Variable Pairs } & Corr & $\hat{\varepsilon}_{i t}, \hat{\varepsilon}_{j t}$ & $\hat{\eta}_{i t}, \hat{\eta}_{j t}$ & $\hat{\varepsilon}_{i t}, \hat{\eta}_{j t}$ \\
\hline AUS RET & NZL RET & 0.37 & & AUS,NZL & \\
\hline AUS RET & USA RET & 0.36 & & AUS,USA & \\
\hline AUT GDP & PHL GDP & -0.40 & AUT,PHL & & \\
\hline AUT RET & NOR RET & 0.43 & & AUT,NOR & \\
\hline BEL RET & BRA RET & -0.38 & & BEL,BRA & \\
\hline BEL RET & FRA RET & 0.41 & & BEL,FRA & \\
\hline BEL RET & MYS RET & -0.36 & & BEL,MYS & \\
\hline BEL RET & NLD RET & 0.62 & & BEL,NLD & \\
\hline BEL RET & CHE RET & 0.50 & & BEL,CHE & \\
\hline BRA RET & CHE RET & -0.42 & & BRA,CHE & \\
\hline CAN RET & NOR RET & 0.47 & & CAN,NOR & \\
\hline CAN RET & PHL RET & -0.38 & & CAN,PHL & \\
\hline CAN RET & USA RET & 0.42 & & CAN,USA & \\
\hline CHE RET & THA RET & -0.47 & & CHE,THA & \\
\hline CHE RET & GBR RET & 0.44 & & CHE,GBR & \\
\hline CHL GDP & MYS RET & -0.36 & & & CHL,MYS \\
\hline CHL GDP & THA RET & -0.39 & & & CHL,THA \\
\hline CHN RET & GBR RET & -0.41 & & $\mathrm{CHN}, \mathrm{GBR}$ & \\
\hline DEU GDP & MYS GDP & -0.36 & DEU,MYS & & \\
\hline DEU RET & ITA RET & 0.43 & & DEU,ITA & \\
\hline DEU RET & MYS RET & -0.36 & & DEU,MYS & \\
\hline DEU RET & NLD RET & 0.51 & & DEU,NLD & \\
\hline DEU RET & PER RET & -0.38 & & DEU,PER & \\
\hline DEU RET & SGP RET & -0.37 & & DEU,SGP & \\
\hline DEU RET & SWE RET & 0.51 & & DEU,SWE & \\
\hline DEU RET & CHE RET & 0.40 & & DEU,CHE & \\
\hline DEU RET & GBR RET & 0.40 & & DEU,GBR & \\
\hline FIN GDP & MEX GDP & 0.37 & FIN,MEX & & \\
\hline FIN RET & PHL RET & -0.39 & & FIN,PHL & \\
\hline FIN RET & SWE RET & 0.64 & & FIN,SWE & \\
\hline FIN RET & THA RET & -0.36 & & FIN,THA & \\
\hline FIN RET & TUR RET & 0.38 & & FIN,TUR & \\
\hline FRA RET & MEX GDP & 0.37 & & & FRA,MEX \\
\hline FRA RET & DEU RET & 0.71 & & FRA,DEU & \\
\hline FRA RET & ITA RET & 0.57 & & FRA,ITA & \\
\hline FRA RET & NLD RET & 0.62 & & FRA,NLD & \\
\hline FRA RET & PER RET & -0.46 & & FRA,PER & \\
\hline FRA RET & SGP RET & -0.41 & & FRA,SGP & \\
\hline FRA RET & ESP RET & 0.46 & & FRA,ESP & \\
\hline FRA RET & SWE RET & 0.54 & & FRA,SWE & \\
\hline FRA RET & CHE RET & 0.58 & & FRA,CHE & \\
\hline FRA RET & THA RET & -0.46 & & FRA,THA & \\
\hline FRA RET & GBR RET & 0.51 & & FRA,GBR & \\
\hline GBR RET & USA RET & 0.53 & & GBR,USA & \\
\hline IDN GDP & CHE GDP & -0.36 & IDN,CHE & & \\
\hline IDN RET & MYS RET & 0.40 & & IDN,MYS & \\
\hline IDN RET & PHL RET & 0.42 & & IDN,PHL & \\
\hline ITA GDP & GBR GDP & 0.39 & ITA,GBR & & \\
\hline ITA RET & NLD RET & 0.43 & & ITA,NLD & \\
\hline ITA RET & PER RET & -0.39 & & ITA,PER & \\
\hline ITA RET & ESP RET & 0.57 & & ITA,ESP & \\
\hline KOR GDP & MYS GDP & 0.46 & KOR,MYS & & \\
\hline KOR RET & NOR RET & -0.38 & & KOR,NOR & \\
\hline KOR RET & THA RET & 0.44 & & KOR,THA & \\
\hline MEX GDP & ESP RET & 0.40 & & & MEX,ESP \\
\hline MYS GDP & SWE GDP & -0.37 & MYS,SWE & & \\
\hline MYS RET & NOR RET & -0.36 & & MYS,NOR & \\
\hline MYS RET & THA RET & 0.40 & & MYS,THA & \\
\hline MYS RET & GBR RET & -0.42 & & MYS,GBR & \\
\hline NLD RET & SWE RET & 0.36 & & NLD,SWE & \\
\hline NLD RET & CHE RET & 0.56 & & NLD,CHE & \\
\hline NLD RET & GBR RET & 0.50 & & NLD, GBR & \\
\hline NLD RET & USA RET & 0.42 & & NLD,USA & \\
\hline SGP RET & ESP RET & -0.43 & & SGP,ESP & \\
\hline SGP RET & THA RET & 0.48 & & SGP,THA & \\
\hline SWE RET & THA RET & -0.47 & & SWE,THA & \\
\hline SWE RET & TUR RET & 0.40 & & SWE,TUR & \\
\hline THA RET & TUR RET & -0.38 & & THA,TUR & \\
\hline
\end{tabular}

Note. Non-zero elements of the regularized error covariance matrix estimate proposed by Bailey et al. (2019).

There are no within-country correlations that are statistically significant. 


\section{B Robustness Results With Alternative Multi-Country Covariance Matrix}

Figure 9 Forecast Error VARiance Decomposition of Country-SPECific Equity Returns: Diagonal Multi-country Covariance Matrix
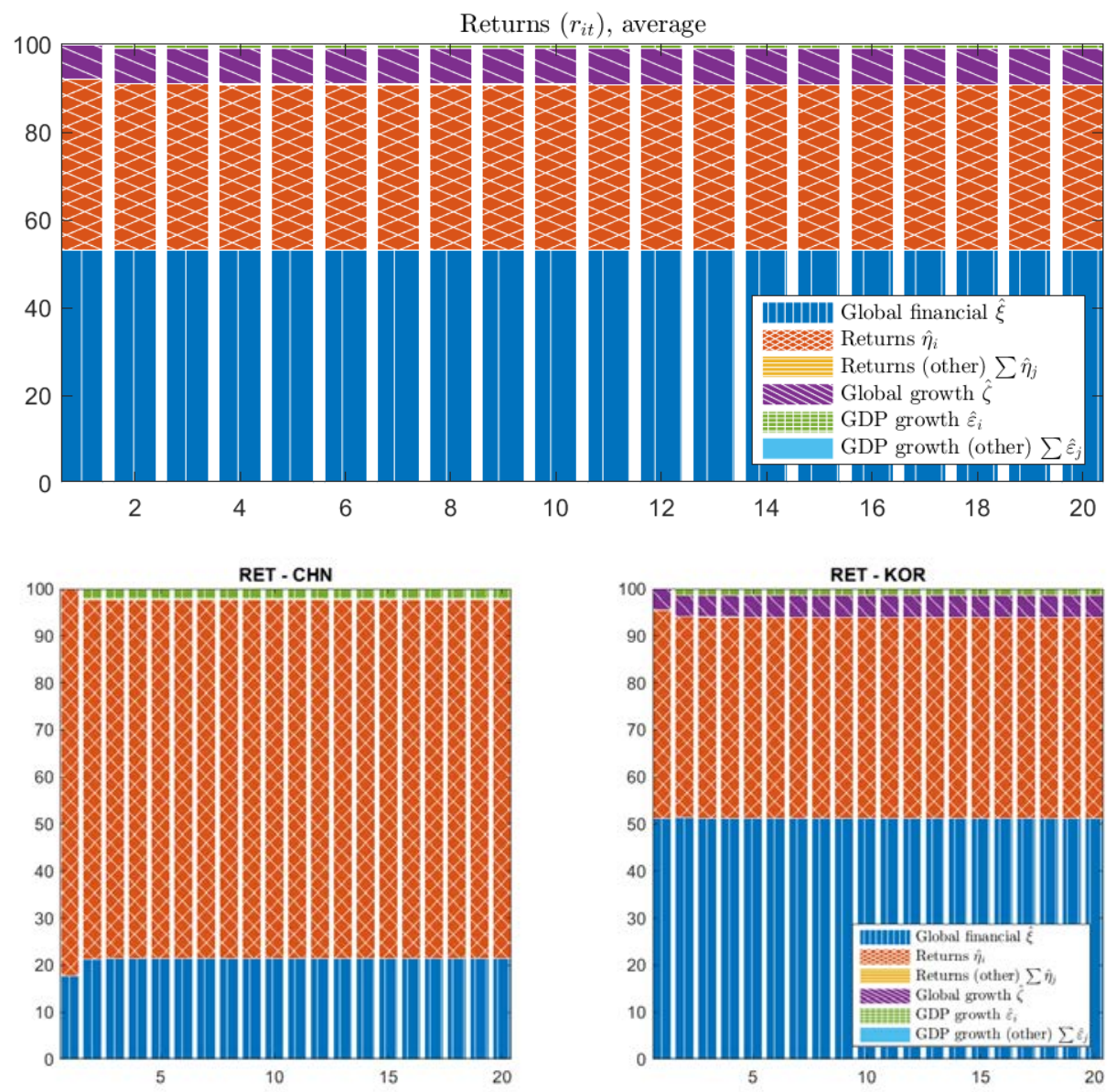

Note. Note: See Figure 6. Forecast error variance decomposition obtained assuming a multi-country diagonal covariance matrix. 
Figure 10 Forecast Error Variance Decomposition of Country-SPecific Output Growths: Diagonal Multi-Country Covariance Matrix
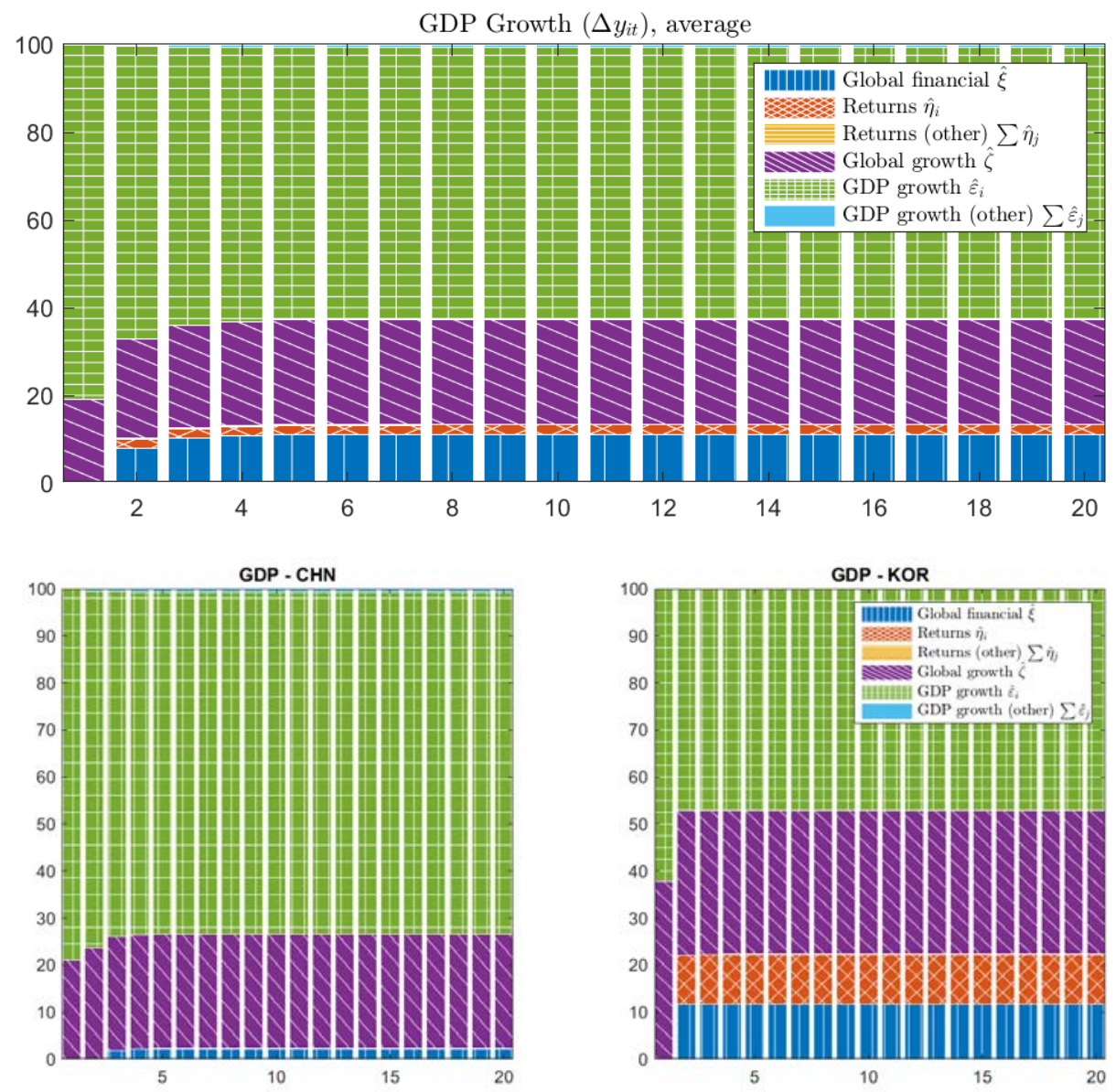

Note. Note: See Figure 6. Forecast error variance decomposition obtained assuming a multi-country diagonal covariance matrix. 
Figure 11 Generalized Forecast Error Variance Decomposition of Country-Specific Equity Returns: Unrestricted Multi-Country Covariance Matrix
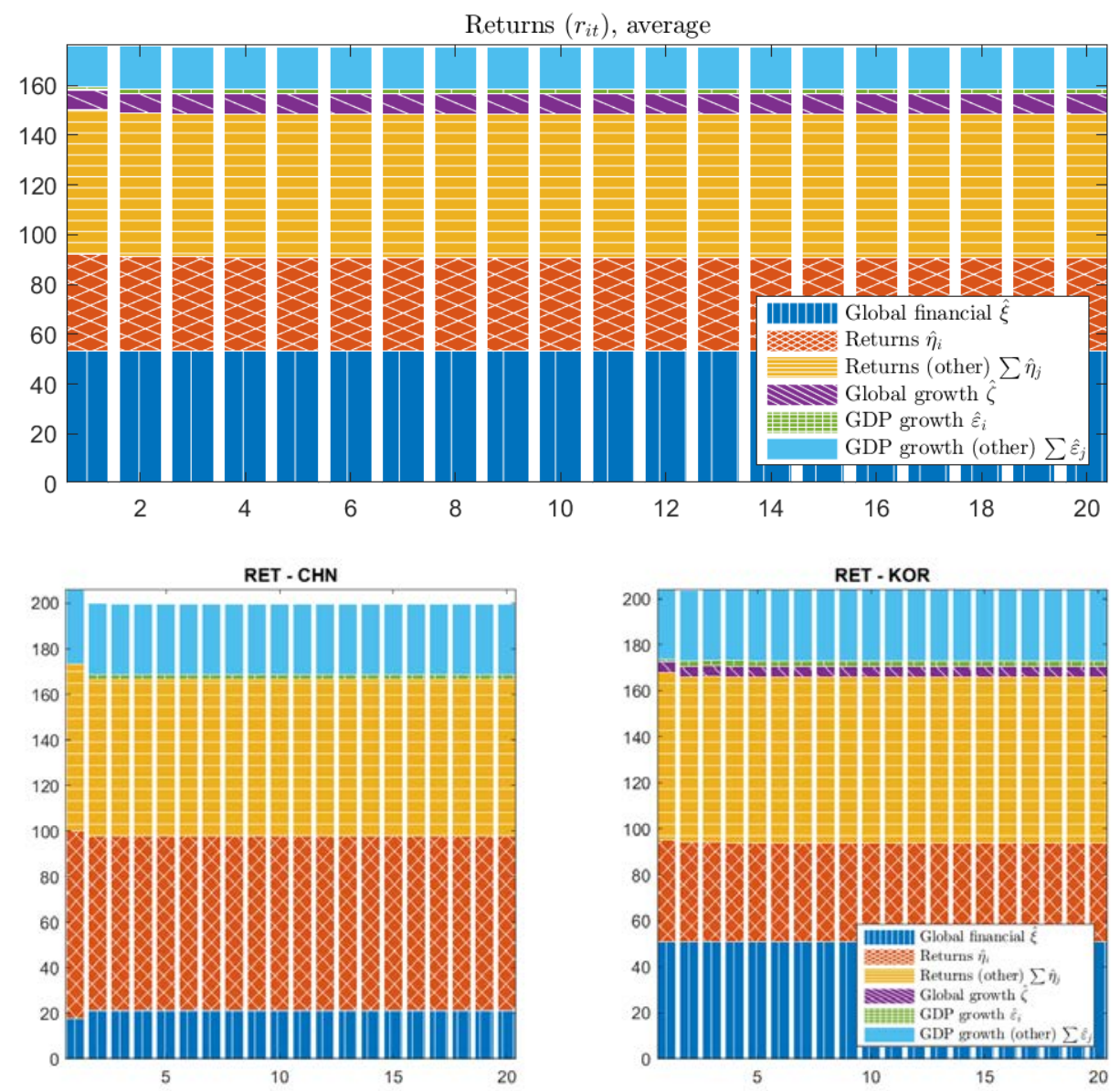

NoтE. Note: See Figure 6. Forecast error variance decomposition obtained assuming an unrestricted multi-country covariance matrix. 
Figure 12 Generalized Forecast Error Variance Decomposition of Country-Specific Output Growths: Unrestricted Multi-Country Covariance Matrix
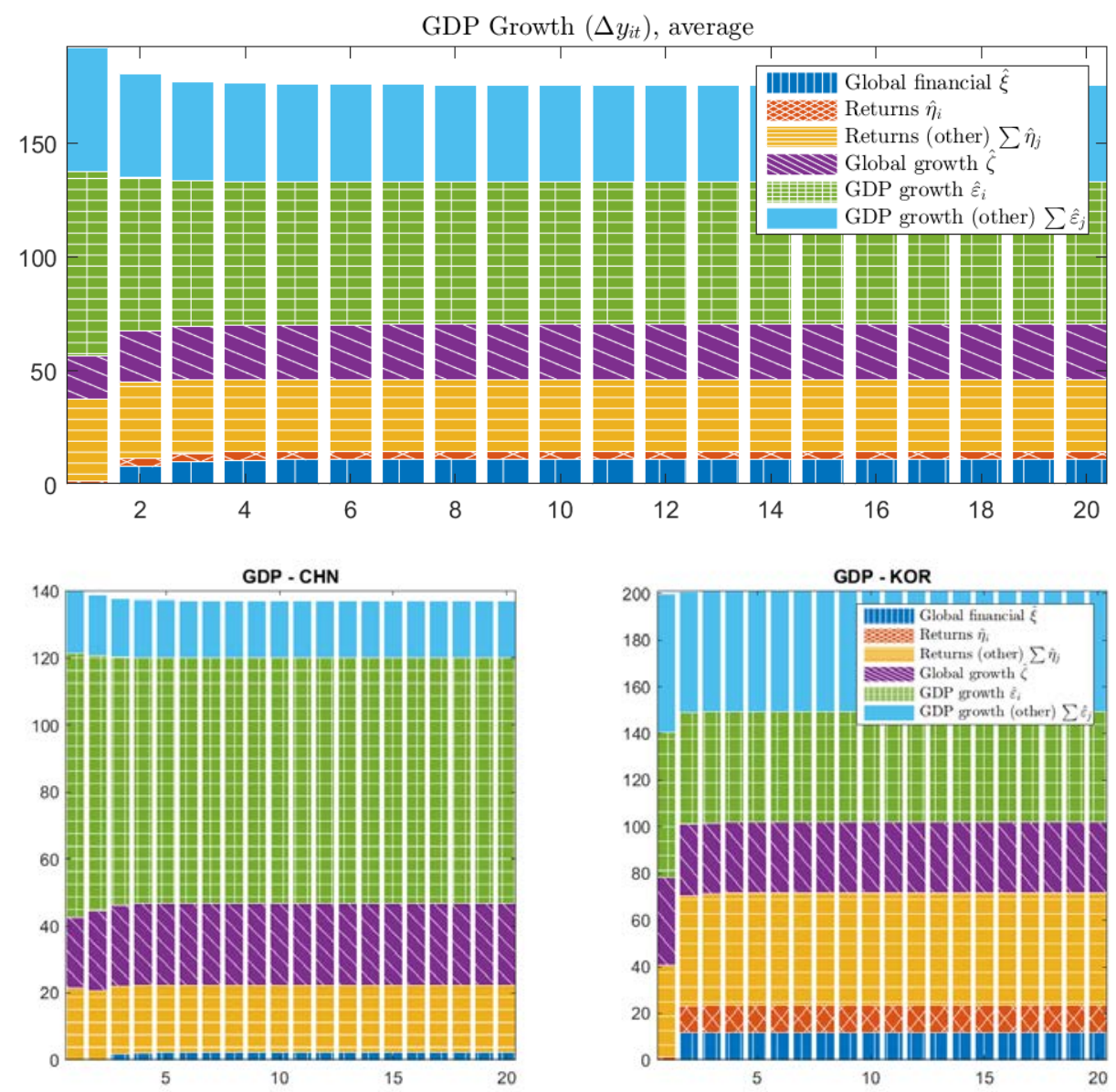

Note. Note: See Figure 6. Forecast error variance decomposition obtained assuming an unrestricted multi-country covariance matrix. 